Atmos. Chem. Phys., 13, 10769-10785, 2013

www.atmos-chem-phys.net/13/10769/2013/

doi:10.5194/acp-13-10769-2013

(c) Author(s) 2013. CC Attribution 3.0 License.

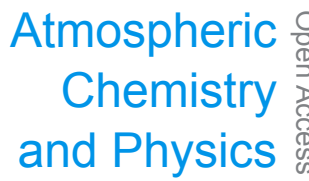

\title{
Heterogeneous formation of polar stratospheric clouds - Part 2: Nucleation of ice on synoptic scales
}

\author{
I. Engel ${ }^{1, *}$, B. P. Luo ${ }^{1}$, M. C. Pitts ${ }^{2}$, L. R. Poole ${ }^{3}$, C. R. Hoyle ${ }^{4,1}$, J.-U. Grooß ${ }^{5}$, A. Dörnbrack ${ }^{6}$, and T. Peter ${ }^{1}$ \\ ${ }^{1}$ Institute for Atmospheric and Climate Science, ETH Zurich, 8092 Zurich, Switzerland \\ ${ }^{2}$ NASA Langley Research Center, Hampton, Virginia 23681, USA \\ ${ }^{3}$ Science Systems and Applications, Incorporated, Hampton, Virginia 23666, USA \\ ${ }^{4}$ Laboratory of Atmospheric Chemistry, Paul Scherrer Institute, 5232 Villigen, Switzerland \\ ${ }^{5}$ Institut für Energie- und Klimaforschung - Stratosphäre (IEK-7), Forschungszentrum Jülich, 52425 Jülich, Germany \\ ${ }^{6}$ Institut für Physik der Atmosphäre, DLR Oberpfaffenhofen, 82230 Oberpfaffenhofen, Germany \\ *now at: Institut für Energie- und Klimaforschung - Stratosphäre (IEK-7), Forschungszentrum Jülich, 52425 Jülich, Germany
}

Correspondence to: I. Engel (ines.engel@alumni.ethz.ch)

Received: 15 March 2013 - Published in Atmos. Chem. Phys. Discuss.: 3 April 2013

Revised: 25 September 2013 - Accepted: 30 September 2013 - Published: 6 November 2013

\begin{abstract}
This paper provides compelling evidence for the importance of heterogeneous nucleation, likely on solid particles of meteoritic origin, and of small-scale temperature fluctuations, for the formation of ice particles in the Arctic stratosphere. During January 2010, ice PSCs (polar stratospheric clouds) were shown by CALIPSO (CloudAerosol Lidar and Infrared Pathfinder Satellite Observations) to have occurred on a synoptic scale ( $\sim 1000 \mathrm{~km}$ dimension). CALIPSO observations also showed widespread PSCs containing NAT (nitric acid trihydrate) particles in December 2009, prior to the occurrence of synoptic-scale regions of ice PSCs during mid-January 2010. We demonstrate by means of detailed microphysical modeling along air parcel trajectories that the formation of these PSCs is not readily reconciled with expectations from the conventional understanding of PSC nucleation mechanisms. The measurements are at odds with the previous laboratory-based understanding of PSC formation, which deemed direct heterogeneous nucleation of NAT and ice on preexisting solid particles unlikely. While a companion paper (Part 1) addresses the heterogeneous nucleation of NAT during December 2009, before the existence of ice PSCs, this paper shows that also the largescale occurrence of stratospheric ice in January 2010 cannot be explained merely by homogeneous ice nucleation but requires the heterogeneous nucleation of ice, e.g. on meteoritic dust or preexisting NAT particles. The required efficiency of the ice nuclei is surprisingly high, namely comparable to that
\end{abstract}

of known tropospheric ice nuclei such as mineral dust particles. To gain model agreement with the ice number densities inferred from observations, the presence of small-scale temperature fluctuations, with wavelengths unresolved by the numerical weather prediction models, is required. With the derived rate parameterization for heterogeneous ice nucleation we are able to explain and reproduce CALIPSO observations throughout the entire Arctic winter 2009/2010.

\section{Introduction}

The crucial role of polar stratospheric clouds (PSCs) for ozone destruction was identified by Solomon et al. (1986) shortly after the discovery of the Antarctic ozone hole (Farman et al., 1985). At that time, PSCs were thought to consist solely of ice, as other types of PSC particles were still unknown, such as nitric acid trihydrate (NAT) crystals or supercooled ternary solution (STS) droplets. However, little was known about PSC formation conditions. Reports about colorful PSC observations above the Scandinavian mountains go back to the late nineteenth century (Stanford and Davis, 1974; Peter and Grooß, 2012). These so-called mother-ofpearl clouds consist of water ice, and their existence requires temperatures low enough to nucleate ice particles despite the extreme dry conditions in the stratosphere. Whereas stratospheric temperatures in the Antarctic winter and spring 
regularly fall below the ice frost point $\left(T_{\text {frost }}\right)$, mean temperatures within the Arctic vortex are warmer, owing to the larger land-ocean contrasts in the Northern Hemisphere generating atmospheric waves, which weaken the Arctic polar vortex, lead to enhanced mixing of warmer air masses from lower latitudes into the polar vortex and increase the synopticscale temperatures (WMO, 1998; Solomon, 2004). However, on local scales, mountain-induced gravity waves cause air parcels to rise with accompanying high cooling rates reaching record low temperatures from time to time (Dörnbrack et al., 1999). This occasionally results in localized ice PSC formation above the Arctic mountains with almost monodisperse particle distributions and, hence, their spectacularly colorful appearance (Carslaw et al., 1998).

Since 2006, the spaceborne lidar CALIOP (Cloud-Aerosol Lidar with Orthogonal Polarization) aboard CALIPSO (Cloud-Aerosol Lidar and Infrared Pathfinder Satellite Observations) has provided a vortex-wide view of PSC seasons and has contributed to our understanding of cloud formation processes (Winker et al., 2009). The Arctic winter 2009/2010 was of particular interest because of a European Union project with a field campaign aiming at a better understanding and the "reconciliation of essential process parameters for an enhanced predictability of Arctic stratospheric ozone loss and its climate interactions" (RECONCILE) (von Hobe et al., 2013). A major finding of Pitts et al. (2011) based on the CALIOP measurements during the Arctic winter 2009/2010 is that widespread PSCs containing NAT particles, albeit in low number densities, were frequently observed in December 2009, some ten days before any ice could have been present in the polar vortex due to the temperatures being well above $T_{\text {frost }}$. This is in contradiction to our previous laboratory-based understanding of NAT formation, which (1) excluded the possibility of homogeneous NAT formation (Koop et al., 1995; Knopf et al., 2002) and (2) found heterogeneous nucleation rates on meteoritic and other material too slow to be an efficient mechanism (Biermann et al., 1996). The only well-characterized pathway to form NAT was downstream of ice clouds through heterogeneous nucleation on ice particles (Luo et al., 2003). However, the new CALIOP observations leave no doubt that there has to be an ice-independent NAT nucleation mechanism. Therefore, the role of particles, possibly consisting of meteoritic material (Curtius et al., 2005) and acting as NAT nuclei, has to be reassessed. This question is addressed in the companion paper by Hoyle et al. (2013), while we show here that there is also evidence for heterogeneous ice nucleation, possibly on the same nuclei.

Dörnbrack et al. (2012) analyzed the meteorological conditions during the Arctic winter 2009/2010. Stratospheric minimum temperatures first fell below the existence temperature of NAT $\left(T_{\mathrm{NAT}}\right)$ in mid-December. A strong and cold vortex was persistent in January with minimum temperatures below $T_{\text {frost }}$ for a week. Synoptic-scale ice clouds were observed during this time period, which is a rare occurrence in the Arctic. Even though 2009/2010 was an Arctic winter with unusually low minimum temperatures, we show here that these temperatures are, in themselves, insufficient to explain the CALIOP ice observations in terms of homogeneous nucleation. Rather, ice nucleates homogeneously only when $T \lesssim T_{\text {frost }}-3 \mathrm{~K}$ (Koop et al., 2000), which according to meteorological temperature data was clearly not reached on synoptic scales. The volume-based nucleation rate coefficient suggested by Koop et al. (2000) aligns with classical nucleation theory and various laboratory studies analyzing ice nucleation within binary and ternary solutions (e.g. Middlebrook et al., 1993; Koop et al., 1998; Chang et al., 1999), whereas the importance of surface-based ice nucleation proposed by Tabazadeh et al. (2002) has not been confirmed.

Since heterogeneous nucleation of NAT is necessary to explain the CALIOP observations in December (when temperatures stayed more than $5 \mathrm{~K}$ above $T_{\text {frost }}-3 \mathrm{~K}$ as shown in Fig. 1 by Hoyle et al., 2013), this suggests that a similar pathway might exist also for ice formation. For the troposphere, different laboratory as well as theoretical studies show that this process is of importance for ice cloud formation (e.g. Zuberi et al., 2002; DeMott et al., 2003; Kärcher and Lohmann, 2003; Cziczo et al., 2013, and references therein). However, little attention has been paid to the implications of heterogeneous ice nucleation for PSC formation, although Bogdan et al. (2003) have shown that fumed silica, possibly representative for meteoritic smoke particles, is suitable to induce heterogeneous freezing of ice under stratospheric conditions. In addition to heterogeneous nucleation of ice on foreign nuclei, the possibility of heterogeneous nucleation on preexisting NAT particles will be investigated. The nucleation of ice on sulfuric acid tetrahydrate (SAT) has also been discussed in the past. However, we do not further investigate this potential ice formation pathway due to unknown formation routes and lack of observational evidence for the existence of SAT (e.g. Lowe and MacKenzie, 2008; Peter and Grooß, 2012). Also, the early onset of NAT formation in December 2009, when the presence of SAT was very unlikely, demands a NAT formation mechanism which can hardly be SAT-induced. Finally, ice or NAT nucleation caused by galactic cosmic or solar energetic particles penetrating STS droplets as proposed by $\mathrm{Yu}$ (2004) is not considered in this study. An extended solar minimum with very low fluxes of solar energetic particles ranging from January 2007 until the middle of 2010 (Mewaldt et al., 2013) turns this option into an unlikely possibility to explain the observations. Galactic cosmic rays remain a possibility that we cannot exclude, but their interannual variability is weak and their microphysical mechanism remains more speculative than the reference to heterogeneous nucleation on the observed undissolved nuclei in the stratospheric background aerosol (for more details see also the Interactive Discussion on this paper).

The approach of this paper is as follows: CALIOP PSC observations from the 2009/2010 winter serve as endpoints of air parcel trajectories, which are based on the 
ERA-Interim reanalysis of the European Centre for Mediumrange Weather Forecasts (ECMWF). Microphysical box model runs including new heterogeneous nucleation pathways for PSC formation were performed along these trajectories. In the immersion mode, we adopt the functional dependence of nucleation on active sites as derived in previous work for Arizona Test Dust (ATD), and show that the assumption of active sites is suitable to describe the behavior of stratospheric ice nuclei. Through model comparisons with CALIOP observational data, we constrain the various parameters controlling the heterogeneous nucleation rate. We then show that the heterogeneous pathway for ice nucleation is in accordance with various time periods of the 2009/2010 Arctic winter and with other Arctic winters. A mountain wave ice cloud has also been studied using wind and temperature fields with different temporal and spatial resolutions. Details of how the heterogeneous nucleation of ice on nanometersized particles is implemented in our box model are explained in Sect. 2. Model results are shown in Sect. 3 including a detailed discussion of the evaluation procedure. Conclusions are provided in Sect. 4.

\section{Observational data and model description}

\subsection{CALIPSO observations}

Since April 2006, the CALIPSO satellite has provided a unique platform for near-global cloud observations. With its extensive coverage in particular in the polar regions, CALIOP is well suited for PSC studies. CALIPSO completes 14.5 orbits per day and reaches latitudes up to $82^{\circ}$ (Winker et al., 2007). Along orbit tracks, the CALIOP lidar performs backscatter measurements at 532 and $1064 \mathrm{~nm}$ and linear depolarization measurements at $532 \mathrm{~nm}$. PSCs are distinguished from the background aerosol as statistical outliers with significant enhancement in the backscatter ratio at $532 \mathrm{~nm}\left(R_{532}\right)$ or in the perpendicular backscatter coefficient $\left(\beta_{\text {perp }}\right)$. Composition classes are discriminated according to Pitts et al. (2009, 2011). Six different composition classes are distinguished from the measured lidar signal, covering STS, mixtures of liquids and NAT particles, and ice PSCs. Liquid / NAT mixtures are further separated according to varying NAT number densities inferred from optical calculations. Mix1 is limited to NAT particles $<10^{-3} \mathrm{~cm}^{-3}$, intermediate number densities of NAT particles are classified as Mix2, and high number density NAT clouds with number densities $>0.1 \mathrm{~cm}^{-3}$ are captured in the Mix2-enh class. In addition to synoptic-scale ice clouds, wave ice with $R_{532}>50$ are treated separately. We note that the "PSC mixture classes" of Pitts and coworkers are very similar to the previously used "PSC types" (e.g. Table 1 of Biele et al., 2001), but through their name make explicit that PSCs are external particle mixtures.
We evaluate the model results by comparing with the spatial pattern of aerosol $R_{532}$ (or the aerosol backscatter, $R_{532}-1$, respectively) and $\beta_{\text {perp }}$, and with the PSC classification of Pitts et al. (2011) as described above. To this end we demand that the model agrees with the spatial patterns of the optical measurements of $R_{532}, \beta_{\text {perp }}$, and mixture classes along individual orbits, as well as with the 2-D scatter plots of aerosol depolarization ratio $\left(\delta_{\text {aerosol }}\right)$ versus inverse backscatter ratio $\left(1 / R_{532}\right)$. To our knowledge this is a PSC modeling approach of hitherto unprecedented rigor. This approach is required to enable identification and quantification of the heterogeneous nucleation pathway.

\subsection{Trajectory calculations}

Based on six-hourly wind and temperature fields from the ERA-Interim reanalysis produced by the ECMWF (Dee et al., 2011) with a horizontal resolution of $1^{\circ} \times 1^{\circ}$, we calculated ten-day backward trajectories using the trajectory module of the Chemical Lagrangian Model of the Stratosphere (CLaMS) (McKenna et al., 2002). In the altitude range of 18 to $26 \mathrm{~km}$, we started backward trajectories every $25 \mathrm{~km}$ horizontally and every $500 \mathrm{~m}$ vertically from CALIPSO orbits. With this mesh of trajectories we cover every 15th CALIOP data point within an orbit curtain, enabling us to reproduce whole orbit scenes within a reasonable computing time. Box model runs were performed forward in time, ending at the point of CALIOP observations. We initialized the model at temperatures above $T_{\mathrm{NAT}}$ to start the calculations from the background aerosol and to avoid the preexistence of PSC particles. The box model trajectory is driven by ERA-Interim temperature and pressure data interpolated to time steps of $15 \mathrm{~min}$. Even though the temporal resolution of the underlying meteorological data is on a six-hourly basis, the shorter trajectory time steps allow for a more accurate spatial representation of the pathway (see Brabec et al., 2012, for a discussion of this point). Additionally, shortrange forecasts were conducted by the Integrated Forecast System of the ECMWF to study the impact of higher temporal and spatial resolutions on the microphysical processes. The forecasts were initialized every $6 \mathrm{~h}$, had a lead time of $5 \mathrm{~h}$, and were run for a period of $24 \mathrm{~h}$. Here, the one-hourly output is used for trajectory calculations of a particular event of mountain-wave-induced PSCs above Greenland. To calculate $T_{\mathrm{NAT}}$ and $T_{\text {frost }}$ along the trajectories, we used $\mathrm{H}_{2} \mathrm{O}$ and $\mathrm{HNO}_{3}$ mixing ratios for the corresponding days from the Aura Microwave Limb Sounder (MLS) (Waters et al., 2006). Daily values were horizontally averaged over cloud-free areas within the vortex and vertically interpolated to starting pressures of the trajectories. We selected the PSC-free areas with the help of nearly coincident CALIOP PSC observations. Spatial and temporal differences between MLS and CALIOP are less than $10 \mathrm{~km}$ and $30 \mathrm{~s}$ after a repositioning of the Aura satellite in April 2008 (Lambert et al., 2012). Vertical along-track resolutions are $3.1 \mathrm{~km}$ to $3.5 \mathrm{~km}$ for $\mathrm{H}_{2} \mathrm{O}$, 
and $3.5 \mathrm{~km}$ to $5.5 \mathrm{~km}$ for $\mathrm{HNO}_{3}$. In addition, Aura MLS $\mathrm{H}_{2} \mathrm{O}$ and $\mathrm{HNO}_{3}$ mixing ratios served as starting values for the calculations and are transported along the trajectories of air parcels serving as input for PSC formation, which enables a point-by-point comparison of model results and observations. However, particle sedimentation is ignored. To cope with this problem, we focused on orbits where the backward trajectories had only short time periods below $T_{\mathrm{NAT}}$. Cases where temperatures were either as cold as $T_{\mathrm{NAT}}$ at the beginning of the trajectory or stayed below $T_{\mathrm{NAT}}-4 \mathrm{~K}$ for longer than $80 \mathrm{~h}$ were removed from our analysis and shaded in the graphical representation of the results; see below.

This modeling approach relies on temperature information obtained from output from the ERA-Interim reanalysis produced by the ECMWF, which assimilates meteorological measurements. Furthermore, MLS measurements hold uncertainties in the gas phase $\mathrm{H}_{2} \mathrm{O}$ and $\mathrm{HNO}_{3}$ mixing ratios, which affect the calculations of $T_{\text {frost }}$ and $T_{\mathrm{NAT}}$. Typical single-profile precisions are 4 to $15 \%$ for $\mathrm{H}_{2} \mathrm{O}$ (Read et al., 2007; Lambert et al., 2007) and $0.7 \mathrm{ppbv}$ for $\mathrm{HNO}_{3}$ (Santee et al., 2007). The daily vortex-averaged data used here are not able to fully resolve fine-scale structures. Therefore, the data may under- or overestimate local maxima or minima, which would also change $T_{\text {frost }}$. An underestimation of the water vapor mixing ratio by $1 \mathrm{ppm}$ would increase $T_{\text {frost }}$ by roughly $1 \mathrm{~K}$. Inaccuracies of a few Kelvin, especially in situations close to $T_{\text {frost }}$ could change the interpretation of results obtained from microphysical PSC studies significantly (Manney et al., 2003). For this study, we compared temperatures from ERA-Interim reanalysis with ECMWF operational analysis and the Goddard Earth Observing System Model, Version 5 (GEOS-5) analysis. We found that temperatures from the ECMWF operational analysis were consistently lower (on average by $1 \mathrm{~K}$ ) during the entire winter than both other temperature data sets. A comparison of both ECMWF data sets with unassimilated measured temperatures from 25 radiosondes, which we launched from Ny-Ålesund (Spitsbergen) and the Finnish Met Service launched from Sodankylä (courtesy of Rigel Kivi), shows the same tendency. ECMWF operational analysis temperatures are colder than temperatures measured above Ny-Ålesund and Sodankylä during January 2010. Therefore we decided to base our analysis on ERA-Interim reanalysis data. Even though we are confident that we have chosen the best meteorological data available for this study, temperature uncertainties exist and remain difficult to quantify.

\subsection{Microphysical box model}

The Lagrangian Zurich Optical and Microphysical box Model (ZOMM) is used to calculate the formation of PSCs. The kinetics of uptake and release of nitric acid and water in STS droplets is determined using pressures from an ion interaction model (Pitzer, 1991; Luo et al., 1995). As already mentioned, the model is initialized at temperatures where background conditions can be assumed. The total number of supercooled binary solution (SBS) droplets is assumed to be equal to $15 \mathrm{~cm}^{-3}$. Half of them are assumed to be pure SBS, log-normally distributed across 26 radii with a mode radius of $70 \mathrm{~nm}$ and a standard deviation of 1.8 , as is characteristic for winter polar stratospheric background conditions (Dye et al., 1992). The other half is assumed to contain a solid core of $20 \mathrm{~nm}$ of an insoluble material with an additional coating of $50 \mathrm{~nm}$, motivated by observations of Curtius et al. (2005). Along the trajectories, allowing for changing pressure and temperature, droplet radii grow and shrink in a full kinetic treatment and without being restricted to the initial log-normal shape of the distribution (Meilinger et al., 1995). Ice or NAT particle nucleation results in initiation of additional size classes as soon as number densities exceed a critical value of $10^{-6} \mathrm{~cm}^{-3}$. Evaporated particles, e.g. after a temperature increase, can be relocated to their original droplet radius. Homogeneous ice nucleation in STS droplets is calculated using rates provided by Koop et al. (2000). Details of the new heterogeneous pathway of ice nucleation are specified in Sect. 2.3.1. Section 2.3.2 deals with NAT nucleation within ZOMM. The output includes, among several other parameters, size-resolved number densities of STS, NAT and ice, which are used in Mie and T-matrix scattering codes (Mishchenko et al., 2010) to compute optical parameters for comparison with CALIOP observations. Liu and Mishchenko (2001) recommended that ice crystals in PSCs be modeled as prolate spheroids with aspect ratios $\leqslant 0.83$ (diameter-to-length ratio). Our calculations show a better agreement with CALIOP maximum values of $\delta_{\text {aerosol }}$ for prolate spheroids with aspect ratios of 0.9 (diameter-tolength ratio). This value has been chosen for both ice and NAT. The refractive index is 1.31 for ice and 1.48 for NAT. For more details see the companion publication as well as the listed literature.

Figure 1 summarizes the homogeneous and heterogeneous pathways of PSC formation, which are accounted for in this study. In previous modeling studies, ice was only allowed to nucleate homogeneously within liquid STS particles at $T \lesssim T_{\text {frost }}-3 \mathrm{~K}$, the temperature at which the supersaturation necessary for homogeneous ice nucleation is reached, and only then was NAT allowed to form on the preexisting ice particles (dashed arrows). Our companion paper (Hoyle et al., 2013) introduced heterogeneous NAT nucleation on foreign nuclei, while within this publication we discuss the possibility of heterogeneous ice formation. These previously not quantified pathways have been implemented into ZOMM and are indicated by solid arrows. In addition, we allow ice to nucleate heterogeneously on NAT particles, also marked by a solid arrow (see Fig. 1).

\subsubsection{Heterogeneous ice nucleation}

According to classical nucleation theory (Pruppacher and Klett, 1996), the heterogeneous rate coefficient $J_{\text {het }}$ for ice 


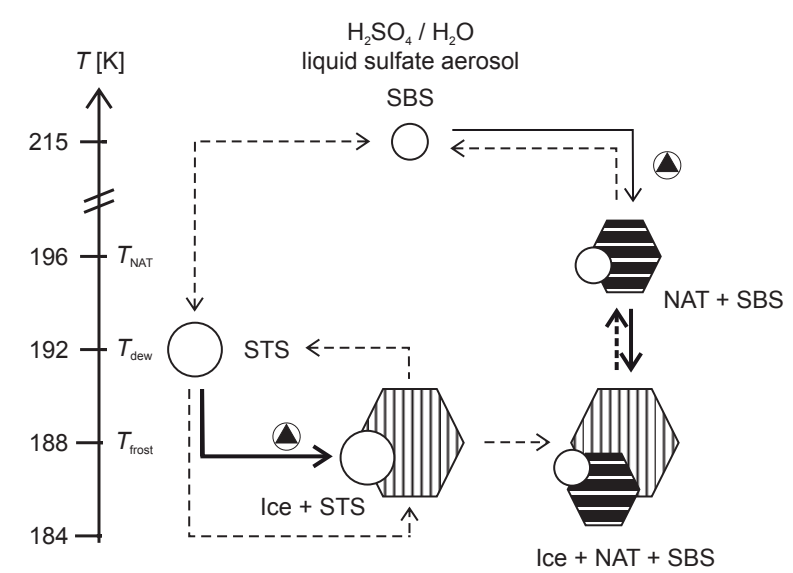

Fig. 1. PSC formation pathways implemented into ZOMM (Zurich Optical and Microphysical box Model) with SBS= supercooled binary solution $\left(\mathrm{H}_{2} \mathrm{SO}_{4} / \mathrm{H}_{2} \mathrm{O}\right) ; \quad \mathrm{STS}=$ supercooled ternary solution $\left(\mathrm{HNO}_{3} / \mathrm{H}_{2} \mathrm{SO}_{4} / \mathrm{H}_{2} \mathrm{O}\right) ; \mathrm{NAT}=$ nitric acid trihydrate $\left(\mathrm{HNO}_{3} \cdot 3 \mathrm{H}_{2} \mathrm{O}\right) ; \boldsymbol{\Delta}=$ foreign nuclei, e.g. meteoritic dust, immersed in STS aerosol droplets (surrounded by circle). Dashed arrows denote pathways included in previous schemes (e.g. following Lowe and MacKenzie, 2008; Peter, 1997). Solid arrows show the heterogeneous nucleation pathways of NAT and ice on preexisting solid particles supported by the new field observations. Thick arrows are discussed within this publication; the thin solid arrow is discussed in companion paper (Hoyle et al., 2013). Note that some arrows are unidirectional (i.e. the other direction is thermodynamically not possible), while others are bidirectional.

nucleation with units of $\mathrm{cm}^{-2} \mathrm{~s}^{-1}$ is dependent on temperature $T$ and can be formulated as

$J_{\text {het }}(T)=\frac{k T}{h} \exp \left[-\frac{\Delta F_{\text {diff }}(T)}{k T}\right] \times n \exp \left[-\frac{\Delta G(T) f_{\text {het }}}{k T}\right]$,

where $k$ is the Boltzmann and $h$ the Planck constant. $n$ is the number density of water molecules at the interface between water and the ice nucleus (IN) and is set to $10^{15} \mathrm{~cm}^{-2}$ (Marcolli et al., 2007). The diffusion activation energy $\Delta F_{\text {diff }}$ and the Gibbs free energy $\Delta G$ are parameterized according to Zobrist et al. (2007) and references therein.

The ice saturation ratio $S$ enters into the calculation of $\Delta G$ and is defined for immersion freezing as

$S(T)=\frac{p_{\text {liq }}(T)}{p_{\text {ice }}(T)}$.

Vapor pressures of liquid water $p_{\text {liq }}$ and ice $p_{\text {ice }}$ are calculated following Murphy and Koop (2005). The compatibility function $f_{\text {het }}$ discriminates homogeneous and heterogeneous nucleation. $f_{\text {het }}$ expresses a reduction of $\Delta G$ needed to form a critical ice embryo and can be written as

$f_{\text {het }}=\frac{1}{4}(2+\cos \alpha)(1-\cos \alpha)^{2}$.

The contact angle $\alpha$ between the ice embryo and the IN can vary from $0^{\circ}$ to $180^{\circ}$, which for small contact angles results in nucleation starting as soon as supersaturation is reached, whereas for large contact angles heterogeneous nucleation is not favored and is comparable to homogeneous nucleation (Seinfeld and Pandis, 2006).

Subsequently, we will utilize a parameterization for ice nucleation on ATD described by Marcolli et al. (2007). They described freezing experiments and observed heterogeneous nucleation over a broad temperature range. They concluded that the ability to nucleate ice varies between different ATD particles and formulated an occurrence probability $\left(P_{\mathrm{as}}\right)$ of so-called active sites:

$P_{\text {as }}(\alpha)=P_{\text {pre }} \times \exp \left(\frac{-51^{\circ}}{\alpha-\alpha_{0}}\right)$.

Active sites are surface inhomogeneities such as steps or cavities, or chemical or electrical inhomogeneities, which are assumed to initiate ice nucleation (Pruppacher and Klett, 1996). Following Marcolli et al. (2007), the mean area of an active site is set to $A_{\text {as }}=10 \mathrm{~nm}^{2}$. Even though a single particle may carry several active sites, only the best active site with the smallest contact angle $\alpha$ is of importance. The occurrence probability of active sites decreases with decreasing $\alpha$. The best fit for ATD in tropospheric ice formation was achieved by assuming the nucleation to follow the singular hypothesis with $\alpha_{0}=46^{\circ}$ and $P_{\text {pre }}=10^{-5}$ for a step width of $1^{\circ}$ (Marcolli et al., 2007). Here, we implement the singular hypothesis of an active site distribution into ZOMM by treating the prefactor $P_{\text {pre }}$ and the most suitable (minimum) contact angle $\alpha_{0}$ as free-fitting parameters to adjust the formulation of $P_{\text {as }}$ to stratospheric conditions, fitted to the CALIOP observations.

Our parameterization of heterogeneous nucleation does not discriminate between different kinds of dust or other solid cores that might be immersed in the stratospheric background aerosol. Not only the composition but also number densities and sizes of interplanetary dust particles comprise a large uncertainty (Plane, 2012). However, our choice of number densities and sizes are in general agreement with studies of meteoritic material, transported from the mesosphere down into the polar vortex. With an average extraterrestrial mass influx of 20 to 100 tons per day (Cziczo et al., 2001), which compares with 160 tons per day of sulfur influx from the troposphere (or 650 tons per day of aqueous sulfuric acid) during volcanically quiescent times (SPARC, 2006), meteoritic material constitutes 3 to $15 \mathrm{wt} \%$ of the stratospheric aerosol. It is spread globally and funneled into the polar winter stratosphere of both hemispheres by the BrewerDobson circulation. For our study, we assume a number density of $7.5 \mathrm{~cm}^{-3}$ of meteoritic particles uniformly distributed throughout the Arctic stratosphere, which results in $50 \%$ of the total background aerosol droplets carrying meteoritic particles. These numbers are a conservative estimate compared to Curtius et al. (2005) and similar measurements performed within RECONCILE (von Hobe et al., 2013). Stratospheric $\mathrm{H}_{2} \mathrm{SO}_{4} / \mathrm{H}_{2} \mathrm{O}$ particle concentrations range from 10 to $20 \mathrm{~cm}^{-3}$, and a higher fraction of nonvolatile compounds 
was measured by Curtius et al. (2005) inside (67\%) the vortex than outside (24\%), supporting the funneling effect mentioned above. The foreign nuclei within ZOMM are represented with a fixed radius of $20 \mathrm{~nm}$ following Hunten et al. (1980), who modeled the recondensation of ablated meteoric material into nanometer-sized smoke particles. Since only a small fraction of the foreign material are assumed to serve as heterogeneous nuclei (Hoyle et al., 2013), a change in number densities or radii of the material present has no effect on the conclusion of this study. A slightly re-tuned parameterization would produce similar results for different percentages of nonvolatile residuals.

Pitts et al. (2011) observed that the increase in synopticscale ice PSCs starting on 15 January 2010 goes along with a decrease in high number density NAT mixtures. During the first two weeks of January 2010, wave ice was the major source of observed Mix2-enh. Decreasing number densities in the Mix2-enh class might be an indicator for nucleation of synoptic-scale ice on these preexisting NAT particles. To substantiate such a dependence, vortex-wide calculations on longer timescales would be needed, and mixing of air masses and a resolution high enough to represent mountain waves would be additional requirements. Our approach is not accurate for simulations lasting over more than a few days. Therefore, we consider heterogeneous nucleation of ice on NAT only in a simplified way with a fixed $\alpha$ of $60^{\circ}$. By using a fixed contact angle, we assume that all NAT particles have an equal efficiency to nucleate ice. This simplification is in agreement with Luo et al. (2003), who made a similar assumption for the converse nucleation of NAT on ice. Since CALIOP observed extensive fields of Mix2-enh only directly after the occurrence of wave-induced ice clouds (Pitts et al., 2011), whereas NAT number densities of Mix1 and Mix2 clouds are more than two orders of magnitude lower than number densities of foreign nuclei, this simplification seems to be sufficient as shown in Sect. 3. Changing $\alpha$ in either direction does not significantly change modeled ice number densities because the result is dominated by either homogeneously nucleated ice (typically in mountain waves) or heterogeneous nucleation of ice on dust particles (on the synoptic scale).

\subsubsection{Heterogeneous NAT nucleation}

Our current understanding of PSC formation includes two mechanisms to nucleate NAT: first, the nucleation scheme of NAT particles forming on solid inclusions, such as meteoritic dust, which is described and discussed in detail in the companion paper by Hoyle et al. (2013); second, the original approach, the formation of NAT on preexisting ice particles, which follows Luo et al. (2003). The parameterization for the nucleation rate for NAT on ice is defined as follows:

$$
\begin{aligned}
& J_{\mathrm{NAT}}(T)=6.24 \times 10^{24} \mathrm{~cm}^{-2} \mathrm{~s}^{-1} \times(T / \mathrm{K}) \\
& \times \exp \left[-\frac{273.15^{3}}{T^{3}} \frac{\gamma}{\left(\ln S_{\mathrm{NAT}}(T)\right)^{2}}-\frac{2000 \mathrm{~K}}{T}\right] .
\end{aligned}
$$

The parameter $\gamma$ was constrained by Luo et al. (2003) to be

$\gamma=\frac{16 \pi m^{2} \sigma^{3} f_{\text {het }}}{3 \rho^{2} k^{3} 273.15^{3}}=328 \mathrm{~K}^{3}$.

The molecular mass of NAT is defined as $m$, while $\rho$ is the density of NAT and $k$ the Boltzmann constant. Unknowns are the surface tension $\sigma$ and $f_{\text {het }}$, which describe the lowering of the Gibbs energy barrier due to the presence of the ice surface. We discuss the importance of changing $\gamma$ in Sect. 3 . The newly developed NAT nucleation parameterization on foreign nuclei differs from Luo et al. (2003) such that $\gamma$ no longer includes the compatibility factor $f_{\text {het }}$ and therefore the parameterization accounts for active sites of different quality. For this reason, Hoyle et al. (2013) defined $\gamma^{\prime}$ - used in our simulations with a value of either $650 \mathrm{~K}^{3}$ or $700 \mathrm{~K}^{3}-$ depending on whether or not small-scale temperature fluctuations are accounted for.

\subsection{Small-scale temperature fluctuations}

Small-scale temperature fluctuations arise from gravity waves, which can be described as an adiabatic displacement of an air parcel (Fritts and Alexander, 2003). Gary (2006) found that fluctuation amplitudes have a strong latitudinal and seasonal dependence and are largest during winter at high latitudes. A comparison between two different sets of aircraft measurements at different flight levels $(\sim 11$ and $18 \mathrm{~km}$ ) showed that amplitudes are larger in the stratosphere than in the troposphere. The underlying terrain, e.g. mountains, has an additional influence (Carslaw et al., 1998). Besides topography, convection and wind shear are further significant sources for gravity waves (Fritts and Alexander, 2003). Several earlier studies investigated the effect of smallscale temperature fluctuations and associated high cooling rates on PSC formation and properties (e.g. Murphy and Gary, 1995; Meilinger et al., 1995; Bacmeister et al., 1999). The effect of different cooling rates on the number density of ice crystals in cirrus clouds was demonstrated by Hoyle et al. (2005) and Kärcher and Lohmann (2003). On synoptic scales with cooling rates of less than one Kelvin per hour, ice number densities remain low and particles can grow to large sizes. In contrast, high cooling rates of several Kelvin per hour result in higher number densities and therefore the ice particles remain smaller. Here we make use of the vertical velocity and temperature time series obtained from the SUCCESS (Subsonic Aircraft: Contrail and Cloud Effects Special Study) data used by Hoyle et al. (2005) to conduct model runs with and without fluctuations to investigate their importance for computed ice cloud properties. The magnitude of the SUCCESS temperature fluctuations is in agreement with the findings by Gary (2006). We prepared a pool 

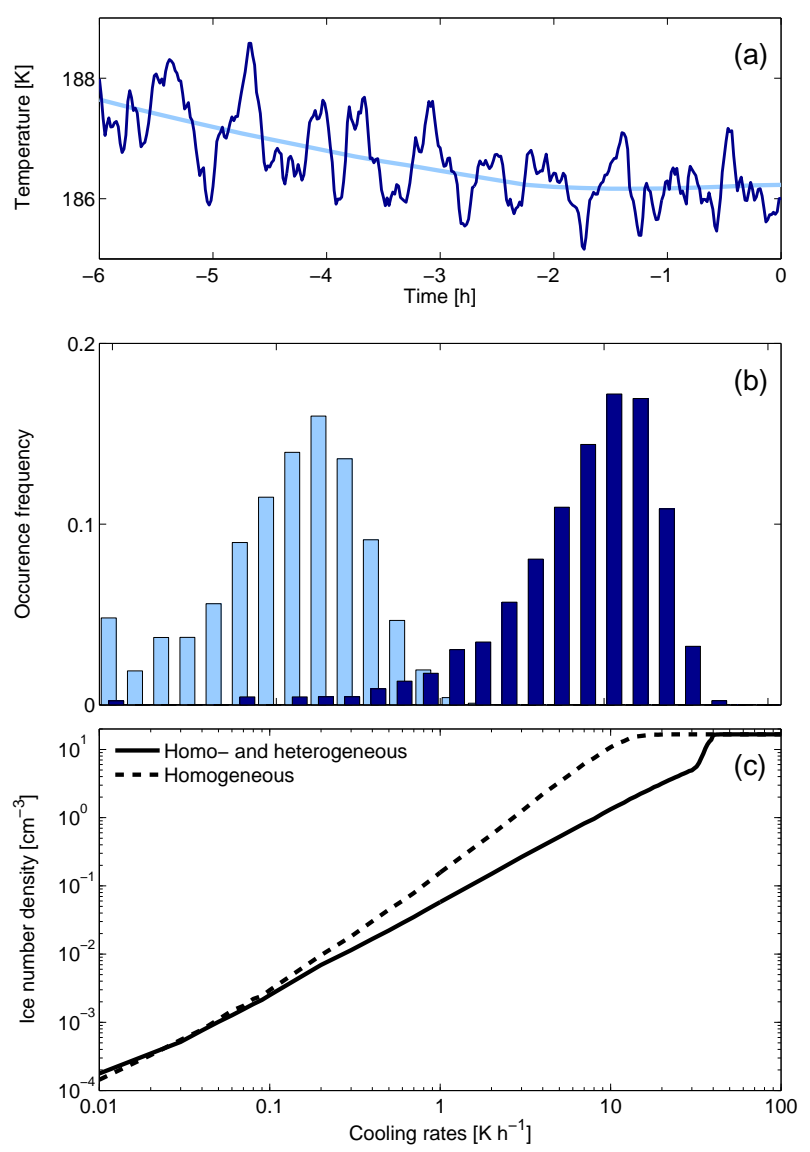

Fig. 2. (a) A typical synoptic-scale ERA-Interim trajectory (light blue), shown together with the same trajectory, with temperature fluctuations superimposed (dark blue). (b) The occurrence frequency of cooling rates on ERA-Interim synoptic-scale trajectories (light blue) and trajectories with superimposed temperature fluctuations (dark blue). (c) Simulated ice number densities versus cooling rates with only homogeneous ice nucleation (dashed curve) and in addition heterogeneous ice nucleation (solid curve).

of 100 different fluctuation time series with a temporal resolution of $1 \mathrm{~min}$, which we superimposed randomly onto the synoptic-scale trajectories. Only wavelengths $<400 \mathrm{~km}$ were considered, which are not resolved in the wind fields used in our trajectory calculations. Mean temperature amplitudes were scaled to $\pm 0.5 \mathrm{~K}$. A typical synoptic-scale trajectory with superimposed temperature fluctuations is shown in Fig. 2a. The distribution of cooling rates taken from a representative number of trajectories with and without fluctuations is illustrated in Fig. 2b. Ice number densities from ZOMM simulations carried out with either homogenous ice nucleation only or homogeneous and heterogeneous ice nucleation in competition are presented in Fig. 2c. Independent of the nucleation mechanism, ice number densities originating from ERA-Interim synoptic-scale cooling rates remain below $\sim 0.1 \mathrm{~cm}^{-3}$. Ice crystal number densities increase with
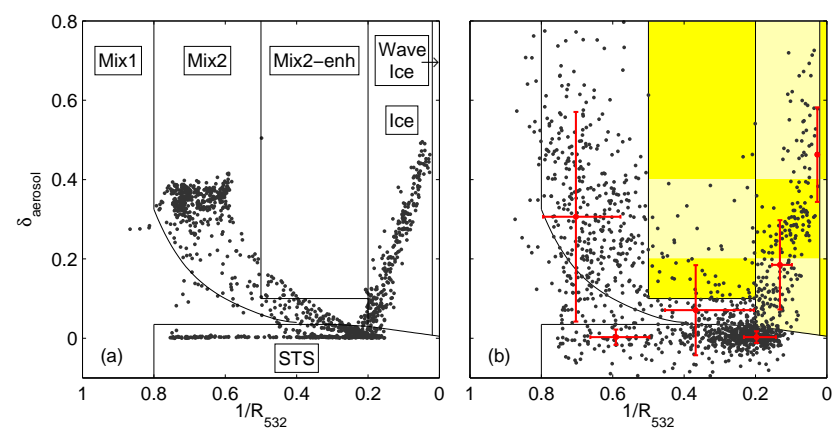

Fig. 3. Simulated model results for an exemplary CALIPSO orbit. Results are shown within the 2-D scatter plot of aerosol depolarization ratio $\left(\delta_{\text {aerosol }}\right)$ versus inverse backscatter ratio $\left(1 / R_{532}\right)$. (a) Unperturbed model results. (b) Model results with CALIOP uncertainties $(\sigma)$ applied. Uncertainties in parallel and perpendicular backscatter are calculated using Eq. (7), propagated into $\delta_{\text {aerosol }}$ and $1 / R_{532}$, and shown as red error bars. Yellow boxes denote a division of the particle classes Mix2-enh, ice and wave ice to quantify the performance of different model runs as discussed in Sect. 3.

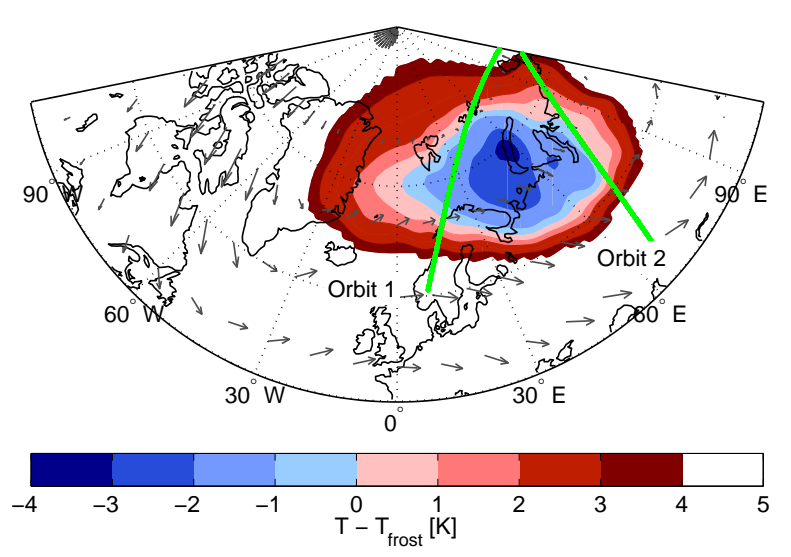

Fig. 4. Geographical location of two selected CALIPSO orbit tracks on 18 January 2010. Referring to the Supplement of Pitts et al. (2011), Orbit 1 is defined as 2010-01-18T01-58-53Z and Orbit 2 as 2010-01-18T21-45-30Z. ERA-Interim wind fields (arrows) and temperatures (color-coded relative to $T_{\text {frost }}$ ) are shown at the $30 \mathrm{hPa}$ pressure level for 12:00 UTC.

increasing cooling rates. At the same time, because heterogeneous nucleation sets in at higher temperatures compared to homogeneous nucleation, the maximum saturation reached is lower, and therefore the number of ice crystals formed is also lower. In the homogeneous case, cooling rates $>10 \mathrm{~K} \mathrm{~h}^{-1}$ enable the entire background aerosol of $15 \mathrm{~cm}^{-3}$ to freeze. In the case of heterogeneous and homogeneous nucleation, cooling rates $>50 \mathrm{~K} \mathrm{~h}^{-1}$ are needed to also activate the remaining $7.5 \mathrm{~cm}^{-3}$, which have no solid inclusion, homogeneously.

Meilinger et al. (1995) demonstrated that the relaxation times for ice and NAT differ greatly due to different partial pressures. While $\mathrm{H}_{2} \mathrm{O}$ reaches equilibrium on a timescale of 
seconds, $\mathrm{HNO}_{3}$ uptake into micron size particles takes hours. During the warming phase of a temperature fluctuation, $\mathrm{H}_{2} \mathrm{O}$ may partition from a liquid droplet back into the gas phase more quickly than $\mathrm{HNO}_{3}$, which causes an increase in the NAT saturation ratio. Small-scale temperature fluctuations lead to an increase in the modeled area of NAT PSCs, as well as an increase in the number densities of NAT particles within the clouds. Hoyle et al. (2013) accounted for the effect of rapid cooling rates by providing two different parameterizations for NAT nucleation, depending on weather or not small-scale fluctuations are resolved by the trajectories.

\subsection{CALIOP comparison}

We estimated the uncertainty $\sigma$ with units of $\mathrm{km}^{-1} \mathrm{sr}^{-1}$ in the CALIOP measurements individually for the parallel and perpendicular backscatter coefficients $\beta$ as follows:

$\sigma(\beta)=\frac{1}{75} \beta \sqrt{\frac{2.39 \times 10^{-5} \mathrm{~km}^{-1} \mathrm{sr}^{-1}}{\beta} \times \frac{1500 \mathrm{~km}}{\Delta_{\text {horizontal }}} \times \frac{5 \mathrm{~km}}{\Delta_{\text {vertical }}} .}$

The uncertainty scales as the square root of the signal $\beta$, inversely as the square root of the horizontal averaging distance $\Delta_{\text {horizontal }}$, and inversely as the square root of the vertical averaging distance $\Delta_{\text {vertical }}$. The observed signal-to-noise ratio ( $\mathrm{SNR}=\beta / \sigma(\beta)$ ) for molecular backscatter at an altitude of $30 \mathrm{~km}\left(\beta=2.39 \times 10^{-5} \mathrm{~km}^{-1} \mathrm{sr}^{-1}\right)$ averaged over $1500 \mathrm{~km}$ horizontally and $5 \mathrm{~km}$ vertically is 75 (Hunt et al., 2009).

We apply the noise level of the satellite data to our model results by calculating $\sigma$ for the simulated parallel and perpendicular backscatter coefficients. Before adding the uncertainty to each component, we scaled those values randomly under the assumption of a normal distribution. The noiseperturbed coefficients were used to further calculate optical properties such as $R_{532}$ and $\delta_{\text {aerosol }}$ for a comparison with CALIOP. Figure 3 gives an example for CALIPSO uncertainties in $\delta_{\text {aerosol }}$ and $1 / R_{532}$. We classified the model output according to Pitts et al. (2011) in the composition classes STS, Mix1, Mix2, Mix2-enh, ice, and wave ice (separated by thin black lines). An altitude-dependent PSC detection threshold for $R_{532}$ and $\beta_{\text {perp }}$ was applied (Pitts et al., 2009) to avoid modeled areas with optical signatures smaller than the noise of the lidar measurement being classified as PSCs.

\section{Results and discussion}

We use two CALIPSO orbit tracks on 18 January 2010 to constrain the fits and compare later with other time periods in January 2010 and with other seasons. The geographical location of the selected orbit tracks is shown in Fig. 4. Orbit 1 (2010-01-18T01-58-53Z) is located upstream of the cold pool of the polar vortex. Temperatures along the associated backward trajectories are lowest at the CALIPSO orbit track. Synoptic-scale areas of ice PSCs were observed during this time of the winter, and Orbit 1 was chosen as being representative for this period. Orbit 2 (2010-01-18T21-45-30Z) is located downstream of Orbit 1 at the eastern edge of the polar vortex. Trajectories ending at Orbit 2 experienced temperatures below $T_{\text {frost }}$ for an extended period of time. The freshly formed ice cloud observed in Orbit 1 has altered while passing through the cold pool of the vortex. At Orbit 2, temperatures are increasing and partly already above $T_{\text {frost }}$. Hence, along Orbit 2, CALIOP observes a mixed-phase PSC dominated by higher number densities of NAT particles (Mix2enh) formed on the preexisting ice.

We compare model runs with different nucleation mechanisms and temperature treatments with CALIOP observations. Figures 5 and 6 summarize the results for Orbit 1 and 2, respectively. The CALIOP measurements are shown in the first column, while the other columns show four different model runs: homogeneous (column 2 and 4 ) and heterogeneous ice nucleation (column 3 and 5) in combination with synoptic-scale temperatures (column 2 and 3) and with superimposed small-scale fluctuations (column 4 and 5). Heterogeneous nucleation of NAT is included in every model run (Hoyle et al., 2013).

The assumption that ice PSCs formed only via homogeneous nucleation requires temperatures $T \lesssim T_{\text {frost }}-3 \mathrm{~K}$. The Arctic stratospheric winter 2009/2010 offered such meteorological conditions but not to the same spatial extent as ice clouds observed by CALIOP. CALIOP observations along Orbit 1 indicate large areas of ice PSCs, even though temperatures along the backward trajectories remained $1.5 \mathrm{~K}$ above the threshold for homogeneous ice nucleation before the point of observation. While the lacking $1.5 \mathrm{~K}$ of additional cooling might be due to uncertainties in the underlying meteorological data, we will see below that homogeneous nucleation, in combination with the ubiquitous temperature fluctuations, leads to ice particle number densities too high to explain the observation. Consequently, model results based merely on classical homogeneous ice nucleation (Fig. 5, column 2) fail to explain the observations. The picture changes by allowing ice to nucleate heterogeneously on foreign nuclei and NAT particles (Fig. 5, column 3). It increases the area of ice coverage by lowering the nucleation barrier. However, calculated aerosol $R_{532}$ and $\beta_{\text {perp }}$ values of the modeled ice particles stay clearly below the maximum values observed (Fig. 5, rows 2-4). The 2-D scatter plot in the bottom row of Fig. 5 illustrates the large discrepancy between model calculations and observations in the ice particle class. Whereas CALIPSO ice observations scatter over the entire range of depolarization, modeled ice particles have a maximum depolarization value of 0.24 (and this value already takes the instrumental noise shown in Fig. 3 into account). Higher ice crystal number densities are required to get a better agreement in the optical parameters (see also theoretical considerations by Pitts et al., 2009). Higher cooling rates are needed, which can be achieved by adding small-scale temperature fluctuations as described in Sect. 2.4. This approach lowers the temperatures along the trajectories occasionally, which causes ice particles to nucleate homogeneously. In the 


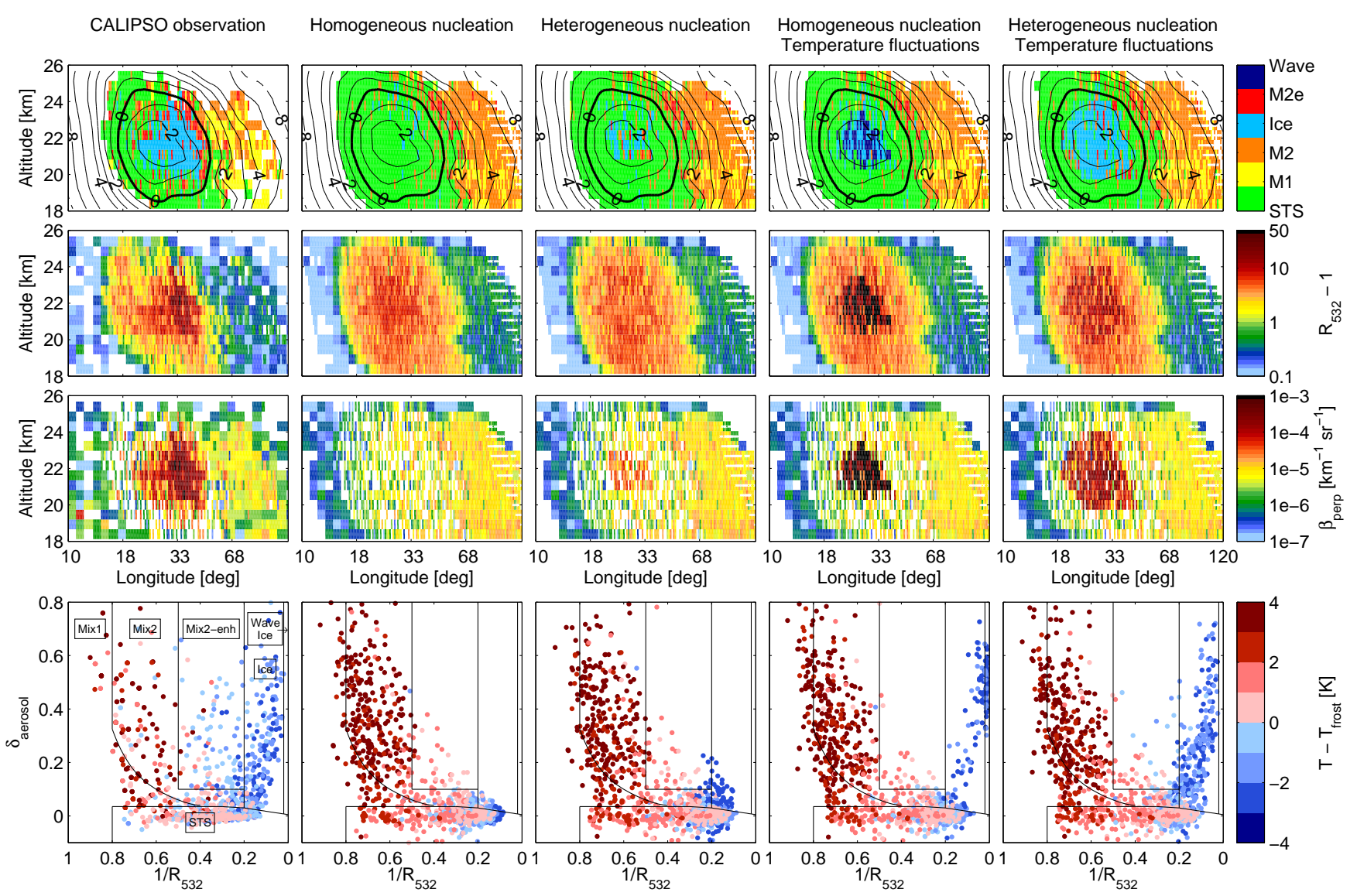

Fig. 5. Orbit 1 on 18 January 2010: CALIPSO orbit track 2010-01-18T01-58-53Z. CALIOP measurements are shown in the first column, model results with varying nucleation mechanism and trajectory temperatures in the subsequent columns. White striped areas indicate trajectories with temperatures below $T_{\mathrm{NAT}}-4 \mathrm{~K}$ longer than $80 \mathrm{~h}$ or temperatures below $T_{\mathrm{NAT}}$ at the trajectory's starting point resulting in an inaccurate initialization. Contour lines and the color-coded data presented in the lowermost row display ERA-Interim temperatures relative to $T_{\text {frost }}$.

case where homogeneous nucleation is the only pathway for ice formation, high levels of supersaturation build up along the trajectory and clouds with optical parameters comparable to wave ice PSCs are generated by the fluctuations on short timescales (Fig. 5, column 4). Only the combination of heterogeneous nucleation, which takes place at lower supersaturation, and small-scale temperature fluctuations leads to a satisfactory agreement between the model and the CALIOP observations (Fig. 5, column 5).

Figure 6 illustrates an identical set of model runs performed for Orbit 2 . The CALIOP observations show predominantly high number density NAT clouds (Mix2, Mix2-enh) with some incorporated ice particles. From our analysis, we conclude that the formation of high number density NAT clouds requires preexisting ice PSCs. The low number density ice clouds formed in model runs without fluctuations do not result in cloud particles classified as Mix2-enh once temperatures increase. Therefore Mix2-enh requires ice in sufficient number densities to serve as heterogeneous NAT nuclei, which follows the traditional concept of ice-induced NAT formation (Peter and Grooß, 2012). Dense NAT clouds were only observed within the polar vortex after the first mountain wave ice PSCs formed at the east coast of Greenland (Pitts et al., 2011). The agreement in the Mix2-enh class relies on a proper simulation of ice number densities upstream on the trajectories. In our analysis this means that only the combination of high cooling rates and heterogeneous ice nucleation allows the successful reproduction of the observed large regions of high number density NAT clouds, Mix2-enh, in the 2-D scatter plot (Fig. 6, column 5).

In addition to the four model treatments discussed so far, free model parameters within the equations governing ice nucleation were also varied to test the model's sensitivity and to support our parameterization. We extended the analysis to five days within the period of synoptic-scale ice (16-20 January 2010). The first orbit of each day corresponds to a situation dominated by synoptic-scale ice, whereas in the second orbit Mix2-enh prevails. The so-called "standard" case in 


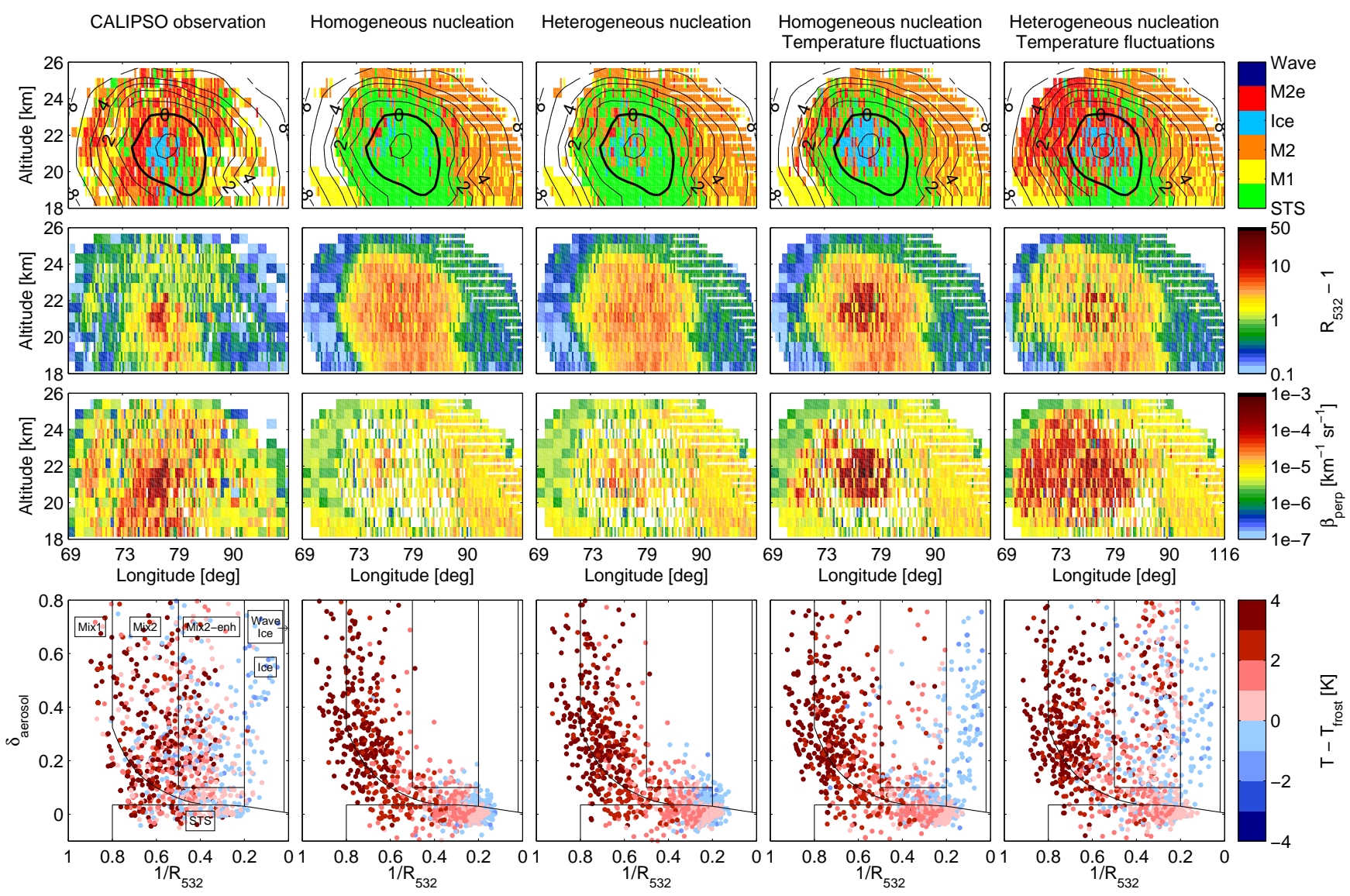

Fig. 6. Same as Fig. 5, but for Orbit 2 on 18 January 2010: CALIPSO orbit track 2010-01-18T21-45-30Z.

Table 1 is highlighted in bold and comprises heterogeneous nucleation of ice on foreign nuclei and NAT as well as superimposed small-scale temperature fluctuations. The standard case is equal to column 5 in Fig. 5 and 6 and is our choice of the best set of fitting parameters. For this sensitivity study, we switched on and off the heterogeneous nucleation pathway for ice, we used trajectories with and without superimposed temperature fluctuations, or varied single parameters, which constrain our new heterogeneous nucleation parameterization. The performance of the different model runs at those selected orbits is judged by the root-mean-square error (RMSE):

$\mathrm{RMSE}=\sqrt{\frac{1}{n} \sum_{i=1}^{n}\left(M_{i}-C_{i}\right)^{2} .}$

We distributed the domain defined by Mix2-enh, ice and wave ice in the $\delta_{\text {aerosol }}$ vs. $1 / R_{532}$ coordinate system into nine boxes (see Fig. 3). Every composition class is divided into three boxes stacked over each other to identify differences in $\delta_{\text {aerosol. }} i$ defines a single box with a total number of $n=9$ such boxes. The difference between the number of hits produced by the model $M$ and the number of measure- ments by CALIOP $C$ is calculated for each grid box $i$. The RMSE describes the mean difference of all boxes. A large RMSE expresses a large difference between model results and measurements. We limited this calculation to Mix2-enh, ice and wave ice since those classes are the focus of this study. The relatively large number of STS particles would otherwise cover the effect of changing ice parameters in the RMSE.

As already discussed, exclusive homogeneous nucleation of ice is not able to explain the observations. The largest errors in Table 1, not only on 18 January but in almost every other case looked at, are associated with runs excluding the possibility of a heterogeneous ice formation pathway. The combination of temperature fluctuations and homogeneous nucleation improves the model performance somewhat, but not in a satisfactory manner, mainly because it cannot account for the large regions with Mix2-enh and keeps overestimating the amount of STS. In cases with homogeneous ice nucleation only, temperature fluctuations lead to the nucleation of ice, but with properties similar to wave ice. The amplitude of the temperature fluctuations is another fitting parameter, and we included simulations with peak-topeak fluctuations half and twice as large as in our standard 
Table 1. Root-mean-square errors (RMSE) of selected ZOMM simulations in comparison to CALIPSO observations (Eq. 8, rounded to next integer). See text for a more detailed description. Calculations are performed with a horizontal resolution of $100 \mathrm{~km}$. In each specific case, only one parameter is changed with respect to the so-called standard case (bold) with the following set of parameters: fluctuations: with; ice on foreign nuclei prefactor: $P_{\text {pre }}=5 \times 10^{-4} \mathrm{deg}^{-1}$; ice on foreign nuclei minimum contact angle: $\alpha_{0}=43^{\circ}$; ice on NAT contact angle: $\alpha=60^{\circ}$; NAT on ice parameter: $\gamma=164 \mathrm{~K}^{3}$. The mean $\bar{x}$ is shown for the parameterization of each specific case averaged over all orbits.

\begin{tabular}{|c|c|c|c|c|c|c|c|c|c|c|c|c|}
\hline Changed quantity & Case & $16 / 1$ & $16 / 2$ & $17 / 1$ & $17 / 2$ & $18 / 1$ & $18 / 2$ & $19 / 1$ & $19 / 2$ & $20 / 1$ & $20 / 2$ & $\bar{x}$ \\
\hline \multicolumn{13}{|c|}{ Only homogeneous ice nucleation } \\
\hline \multirow[t]{2}{*}{ fluctuations } & without & 11 & 11 & 9 & 12 & 9 & 11 & 9 & 12 & 5 & 5 & 9.4 \\
\hline & with & 10 & 9 & 8 & 9 & 8 & 8 & 9 & 10 & 4 & 5 & 8.0 \\
\hline \multicolumn{13}{|c|}{ In addition heterogeneous ice nucleation } \\
\hline standard & $\begin{array}{l}\text { with; } 43^{\circ} ; 5 \times 10^{-4} / \mathrm{deg} \\
60^{\circ} ; 164 \mathrm{~K}^{3}\end{array}$ & 4 & 6 & 4 & 5 & 4 & 6 & 4 & 5 & 3 & 3 & 4.5 \\
\hline \multirow[t]{3}{*}{ fluctuations } & without & 10 & 10 & 9 & 13 & 7 & 11 & 8 & 12 & 5 & 5 & 9.0 \\
\hline & $\div 2$ & 7 & 8 & 8 & 10 & 5 & 6 & 6 & 9 & 4 & 5 & 6.7 \\
\hline & $\times 2$ & 8 & 5 & 7 & 12 & 11 & 22 & 8 & 16 & 6 & 6 & 10.1 \\
\hline \multirow[t]{2}{*}{ ice on nuclei $\left(\alpha_{0}\right)$} & $-10^{\circ}\left(33^{\circ}\right)$ & 4 & 5 & 4 & 5 & 6 & 7 & 5 & 9 & 4 & 2 & 5.2 \\
\hline & $+10^{\circ}\left(53^{\circ}\right)$ & 6 & 7 & 6 & 6 & 4 & 4 & 4 & 6 & 4 & 4 & 5.1 \\
\hline \multirow[t]{2}{*}{ ice on nuclei $\left(P_{\text {pre }}\right)$} & $\times 10\left(5 \times 10^{-3} / \mathrm{deg}\right)$ & 6 & 6 & 4 & 3 & 6 & 5 & 4 & 4 & 4 & 3 & 4.6 \\
\hline & $\div 10\left(5 \times 10^{-5} / \mathrm{deg}\right)$ & 6 & 7 & 6 & 5 & 5 & 2 & 4 & 6 & 4 & 3 & 4.8 \\
\hline \multirow[t]{2}{*}{ ice on NAT $(\alpha)$} & $-20^{\circ}\left(40^{\circ}\right)$ & 5 & 8 & 4 & 4 & 3 & 3 & 5 & 5 & 4 & 4 & 4.6 \\
\hline & $+20^{\circ}\left(80^{\circ}\right)$ & 4 & 5 & 4 & 4 & 4 & 8 & 5 & 6 & 3 & 4 & 4.7 \\
\hline \multirow[t]{2}{*}{ NAT on ice $(\gamma)$} & $\div 2\left(82 \mathrm{~K}^{3}\right)$ & 5 & 5 & 4 & 6 & 6 & 11 & 4 & 8 & 3 & 3 & 5.5 \\
\hline & $\times 2\left(328 \mathrm{~K}^{3}\right)$ & 5 & 7 & 5 & 10 & 5 & 11 & 4 & 11 & 3 & 4 & 6.5 \\
\hline
\end{tabular}

case. Whereas too-large temperature amplitudes result in excess wave ice, amplitudes which remain too small underestimate ice number densities. Differences in the RMSE become smaller for changes of the individual fitting parameters defined in Sect. 2.3. A decrease or increase of the minimum contact angle (compare $\alpha_{0}$ in Eq. 4) results in ice nucleation at higher or lower temperatures, respectively. Both options have a mean RMSE larger than those for $\alpha_{0}=43^{\circ}$. Furthermore, we do not assume a change in the active site properties throughout the winter. Possibly, vertical redistribution due to particle sedimentation could lower the availability of good active sites, which would then favor changing $\alpha_{0}$ to values larger than $43^{\circ}$. The prefactor $\left(P_{\text {pre }}\right.$ in Eq. 4$)$ scales the number density of ice particles. Decreasing (increasing) $P_{\text {pre }}$ results in lower (higher) number densities of ice particles. While the error calculation suggests a relatively weak dependence, plots provided in the Supplement demonstrate this effect clearly. Orbit $16 / 1$ is a good example to see how changing $P_{\text {pre }}$ moves points within the 2-D scatter plot. As already mentioned in Sect. 2.3.1, the fixed $\alpha$ for ice on NAT originates in the assumption that this parameter is quite insensitive within this study and ice number densities are much more dependent on heterogeneous nucleation on foreign nuclei and homogeneous nucleation rather than on the nucleation on preexisting low number density NAT particles. The numbers in Table 1 show no clear trend for changing $\alpha$ in either direction. A change of $\pm 20^{\circ}$ would be nearly as good as the standard case. The parameter $\gamma$ for NAT nucleation

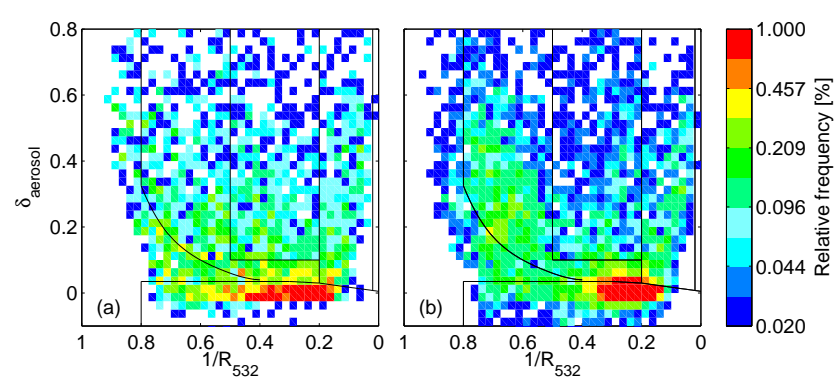

Fig. 7. Normalized composite 2-D histogram of CALIOP PSC observations (a) and simulated PSCs (b) from selected orbits (standard case shown in Table 1) within the period of synoptic-scale ice during the 2009/2010 Arctic winter over the altitude range from 18 to $26 \mathrm{~km}$.

on ice refers to Eqs. (5) and (6). Whereas Luo et al. (2003) found $328 \mathrm{~K}^{3}$ to be the best fit, we show that NAT might nucleate onto ice particles with a nucleation barrier half as large. The value of $\gamma=164 \mathrm{~K}^{3}$ is defined by Luo et al. (2003) as the lower limit, which is still in agreement with the analyzed observations from January 1995 and 1997. Whereas Luo et al. (2003) were limited to four PSC lidar observations, our analysis is based on multiple CALIPSO orbits throughout the 2009/2010 Arctic winter. Orbit 17/2, 18/2 and 19/2 clearly indicate that the original value of $\gamma=328 \mathrm{~K}^{3}$ cannot reproduce Mix2-enh observations by CALIPSO. 


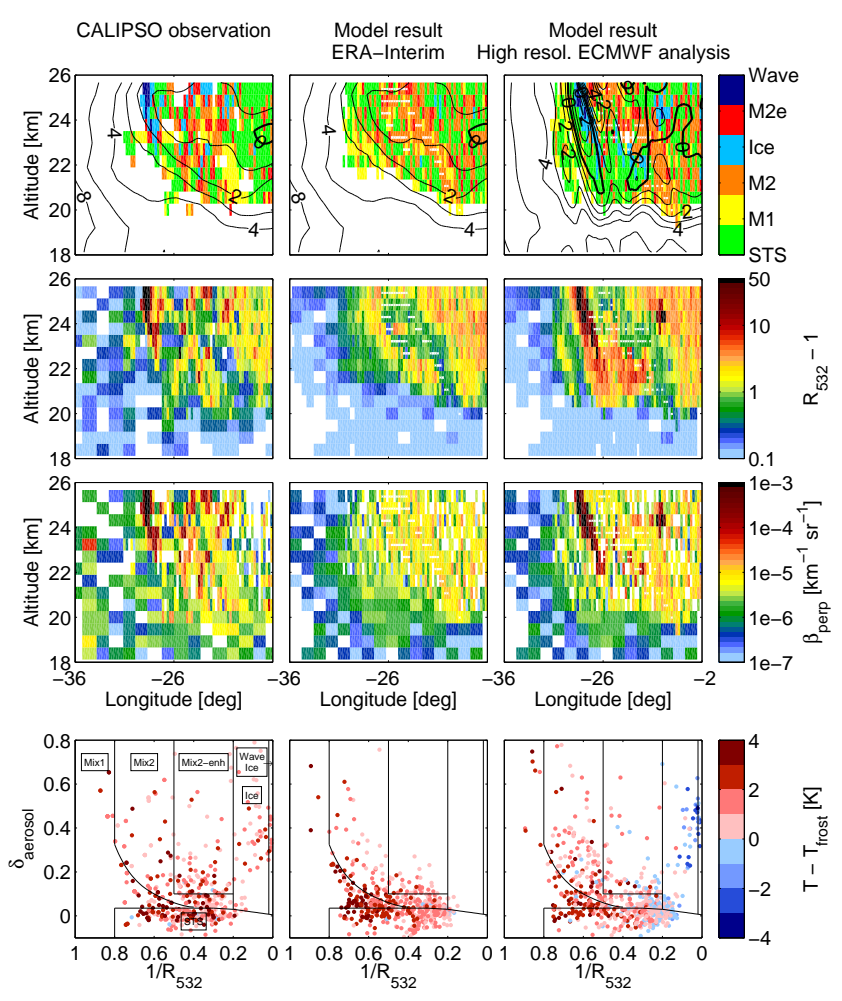

Fig. 8. 4 January 2010: CALIPSO orbit track 2010-01-04T05-0343Z. CALIOP measurements are shown in the left column, model results based on ERA-Interim temperature data in the middle column and model results based on high-resolution ECWMF analysis temperature data in the right column. White striped areas indicate trajectories with temperatures below $T_{\mathrm{NAT}}-4 \mathrm{~K}$ longer than $80 \mathrm{~h}$ or temperatures below $T_{\mathrm{NAT}}$ at the trajectory's starting point. Contour lines and the color-coded data presented in the lowermost row display ERA-Interim temperatures relative to $T_{\text {frost }}$ in the left and middle column and ECMWF analysis temperatures in the right column.

Overall, our parameterization gives consistently good results. In specific cases, different model parameters might yield better performance than our standard values, and it remains difficult to constrain single parameters against the background of temperature and water vapor inaccuracies and unknown nuclei properties. Nevertheless, we clearly demonstrated the necessity of heterogeneous ice nucleation on preexisting solid particles in combination with small-scale temperature fluctuations. The overall model performance and its agreement with the CALIOP measurements in mid-January is summarized in Fig. 7. Following Pitts et al. (2011), we created a 2-D histogram of more than 5000 microphysical model results performed with our standard set of parameters for the period of widespread ice cloud observations and compared those to the associated CALIOP measurements. Although the overall agreement is very good, the model produces more points in the Mix2 class than CALIOP observes. This might be an artifact of missing sedimentation in ZOMM. NAT num-
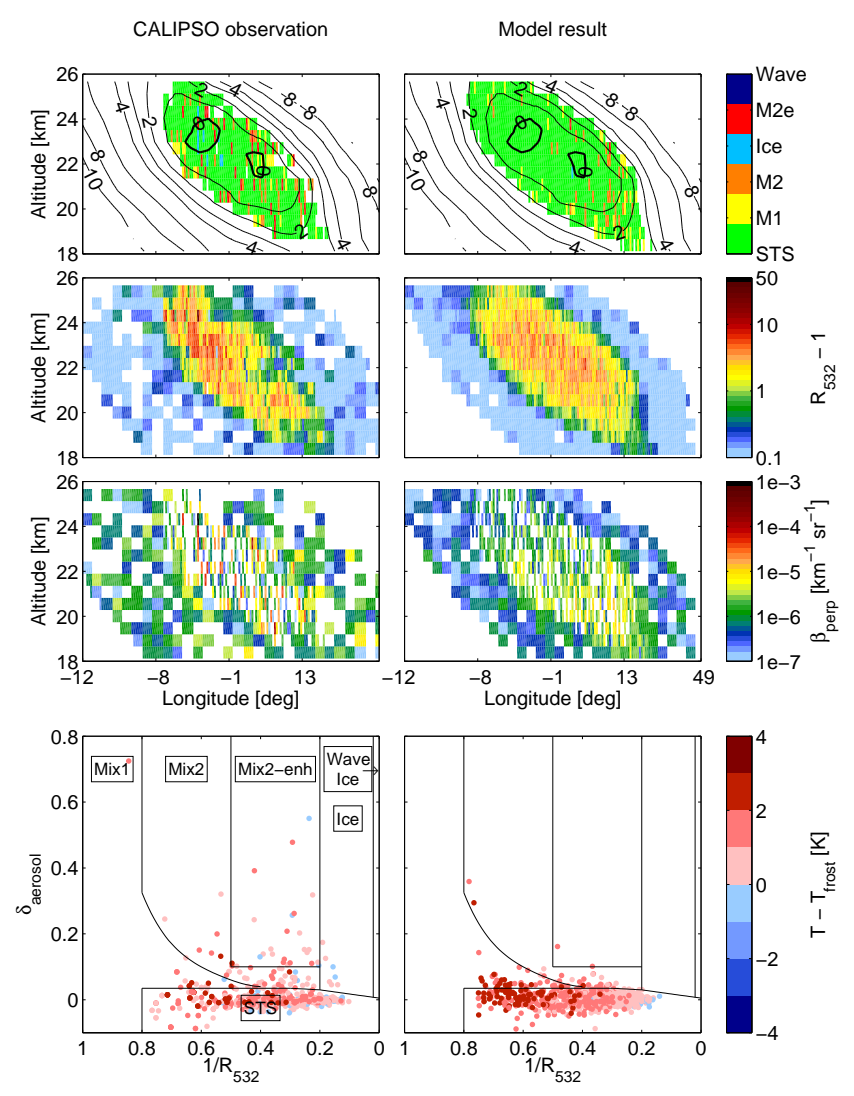

Fig. 9. 24 January 2010: CALIPSO orbit track 2010-01-24T03-0102Z. CALIOP measurements are shown in the left column, model results in the right column. Contour lines and the color-coded data presented in the lowermost row display ERA-Interim temperatures relative to $T_{\text {frost }}$.

ber densities might be reduced or enhanced by accounting for a vertical redistribution of large-enough PSC particles, by falling out, falling through or accumulating in the corresponding cloud layer.

We extended our analysis to the remaining time periods of the 2009/2010 Arctic winter to cover, together with the companion paper by Hoyle et al. (2013), each of the four periods defined by Pitts et al. (2011). In mid-December, the vortex was located over the Canadian sector of the Arctic and cooled gradually through mid-January 2010 (Dörnbrack et al., 2012). The stability of the vortex allowed air parcels to stay within the cold pool of the vortex and led to long exposure times of temperatures below $T_{\mathrm{NAT}}$. Numerous wave ice PSCs appeared over the east coast of Greenland at the beginning of January 2010. Figure 8 compares CALIOP observations on 4 January 2010 to our model results. Focusing on the wave ice cloud above Greenland (seen in the upper left panel of CALIOP observations), cooling rates $>10 \mathrm{Kh}^{-1}$ at the onset of ice nucleation are needed for freezing of the entire background aerosol population (Fueglistaler et al., 2003). The ERA-Interim temperature analysis with a 


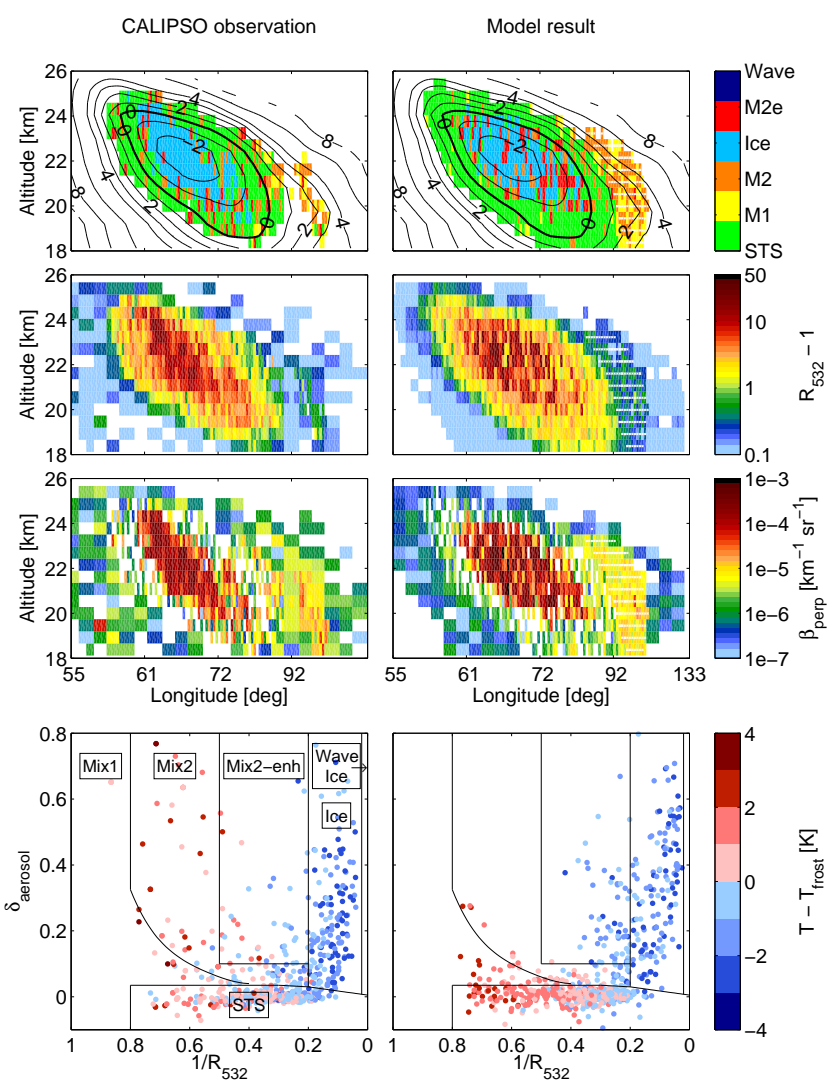

Fig. 10. 26 February 2011: CALIPSO orbit track 2011-02-26T2309-10Z. CALIOP measurements are shown in the left column, model results in the right column. White striped areas indicate trajectories with temperatures below $T_{\mathrm{NAT}}-4 \mathrm{~K}$ longer than $80 \mathrm{~h}$ or temperatures below $T_{\mathrm{NAT}}$ at the trajectory's starting point. Contour lines and the color-coded data presented in the lowermost row display ERA-Interim temperatures relative to $T_{\text {frost }}$.

horizontal resolution of $1^{\circ} \times 1^{\circ}$ misses the wave activity over Greenland entirely, and corresponding temperature contour lines in the two upper left panels of Fig. 8 do not show any anomalies. Dörnbrack et al. (2012) based their analysis of stratospheric gravity waves on ECMWF operational analysis with a $0.25^{\circ} \times 0.25^{\circ}$ grid and derived a correlation between stratospheric temperature anomalies and the magnitude of the horizontal divergence. This result motivated us to redo our analysis with trajectories based on these higherresolution data sets. If the horizontal resolution of the input temperature data is fine enough to capture mountain-induced gravity waves, then ZOMM reproduces wave ice clouds satisfactorily (Fig. 8, column 3). Simultaneous to the occurrence of wave ice PSCs, a remarkable increase in Mix2 and Mix2enh NAT cloud occurrence was detected (Pitts et al., 2011). From our study, we can conclude that ice is a prerequisite for the formation of high number density NAT clouds, though synoptic-scale ice is sufficient to form Mix2-enh and wave ice is not necessary. To model the dependency of NAT from wave ice, vortex-wide simulations including processes like mixing and sedimentation on the basis of high-resolution meteorological data would be necessary and will be considered in future work.

The PSC season ended in late January 2009/2010, at which time the vortex was dominated by STS clouds. The model is able to reproduce these liquid clouds as illustrated in Fig. 9. Even though temperatures were still slightly below $T_{\text {frost }}$, our temperature threshold for heterogeneous ice nucleation seems sufficient to prevent the nucleation of ice. This goes along with the observations of essentially no ice PSCs and less liquid/NAT mixtures than during the earlier period. Near the end of January, the final breakdown of the vortex finished the PSC season of the winter 2009/2010.

Compared to previous and following winters, the 2009/2010 winter was unusually cold from mid-December until the end of January. Within this particular winter, CALIPSO observed more PSCs than in the three previous Arctic seasons combined. Moreover, it was one of only few Arctic winters with synoptic-scale temperatures below $T_{\text {frost }}$, and the occurrence of ice PSC observations was exceptional in the CALIOP record (Pitts et al., 2011). Looking at Arctic winters other than 2009/2010, the number of similar orbits with ice observations not related to strong mountain wave activity is limited. We performed simulations for selected CALIOP orbits from the Arctic winters 2007/2008 and 2010/2011, and Fig. 10 illustrates that the heterogeneous ice nucleation mechanisms are required in other years as well. Attempted simulations performed for the Antarctic reveal that sedimentation cannot be neglected, which we will investigate in future research. Moreover, we will concentrate on the question of whether the Arctic winter 2009/2010 might have been exceptional with regard to the supply of heterogeneous nuclei.

\section{Conclusions}

Spaceborne lidar observations by CALIOP have been analyzed by extensive trajectory and microphysical box model calculations to review PSC ice formation processes. The Arctic winter 2009/2010 was the focus of the RECONCILE project, and the meteorological situation of that winter enabled us to discover inconsistencies in our former understanding of NAT and ice nucleation. Hoyle et al. (2013) showed that NAT particles observed in December 2009 can only be explained by heterogeneous nucleation on preexisting solid particles. Although an ice-independent mechanism of NAT nucleation has been discussed earlier, its necessity has never been observed as clearly as in this particular winter. Furthermore, synoptic-scale temperatures dropped below $T_{\text {frost }}$ in January 2010 for several days. Despite those low temperatures, which are exceptional for the Arctic, the widespread synoptic-scale ice clouds seen by CALIOP cannot be explained solely by homogeneous ice nucleation. 
Rather a pathway of heterogeneous ice nucleation is required in our microphysical model to reconcile the results with observations. The origin of the nuclei can possibly be explained by meteoritic dust, but this remains speculative as long as chemical analyses of the dust particles are lacking. Equally important for the reconciliation of model results with observations is the influence of small-scale temperature fluctuations on cloud properties. Sufficiently rapid cooling is required to obtain ice number densities with optical signatures as large as those observed by CALIOP. Furthermore, we conclude that the formation of high number density NAT clouds is related to preexisting ice particles. Spot tests show that the proposed mechanisms are applicable throughout the whole winter. Whereas a meteorological data set with a horizontal resolution of $1^{\circ} \times 1^{\circ}$ is sufficient for simulations of synopticscale ice, trajectories calculated from higher spatial resolutions are necessary to reproduce wave ice. However, uncertainties in temperature fields and neglect of sedimentation leave room for interpretation, and further research is required with large-scale models applying the nucleation parameterizations developed in the present work.

Tabulated NAT and ice nucleation rates can be derived from the present work, which allows straightforward implementation of the new parameterization into large-scale models. Such an approach reflects the nucleation process far more realistically than current methods involving constant nucleation rates. The use of the new parameterization in threedimensional models, such as in the recent CLaMS study presented by Grooß et al. (2013), should lead to improved representation of dehydration and denitrification and thus better simulations of ozone loss.

\section{Supplementary material related to this article is available online at http://www.atmos-chem-phys.net/13/ 10769/2013/acp-13-10769-2013-supplement.zip.}

Acknowledgements. This work was supported by the European Commission Seventh Framework Programme (FP7) under the grant number RECONCILE-226365-FP7-ENV-2008-1 as well as by the Swiss National Science Foundation (SNSF) (grant numbers 200021 120175/1 and 200021 140663). Support for L. R. Poole is provided under NASA contract NNL11AA10D. Support for B. P. Luo by the project RECONCILE funded by the European Commission is gratefully acknowledged. Aura MLS gas species data were obtained through the Aura MLS website (http://mls.jpl.nasa.gov/index-eos-mls.php).

Edited by: F. Khosrawi

\section{References}

Bacmeister, J. T., Eckermann, S. D., Tsias, A., Carslaw, K. S., and Peter, T.: Mesoscale temperature fluctuations induced by a spectrum of gravity waves: A comparison of parameterizations and their impact on stratospheric microphysics, J. Atmos. Sci., 56, 1913-1924, doi:10.1175/15200469(1999)056<1913:MTFIBA>2.0.CO;2, 1999.

Biele, J., Tsias, A., Luo, B. P., Carslaw, K. S., Neuber, R., Beyerle, G., and Peter, T.: Nonequilibrium coexistence of solid and liquid particles in Arctic stratospheric clouds, J. Geophys. Res., 106, 22991-23007, doi:10.1029/2001JD900188, 2001.

Biermann, U. M., Presper, T., Koop, T., Mossinger, J., Crutzen, P. J., and Peter, T.: The unsuitability of meteoritic and other nuclei for polar stratospheric cloud freezing, Geophys. Res. Lett., 23, 1693-1696, doi:10.1029/96GL01577, 1996.

Bogdan, A., Molina, M. J., Kulmala, M., MacKenzie, A. R., and Laaksonen, A.: Study of finely divided aqueous systems as an aid to understanding the formation mechanism of polar stratospheric clouds: Case of $\mathrm{HNO}_{3} / \mathrm{H}_{2} \mathrm{O}$ and $\mathrm{H}_{2} \mathrm{SO}_{4} / \mathrm{H}_{2} \mathrm{O}$ systems, J. Geophys. Res., 108, 4302, doi:10.1029/2002JD002605, 2003.

Brabec, M., Wienhold, F. G., Luo, B. P., Vömel, H., Immler, F., Steiner, P., Hausammann, E., Weers, U., and Peter, T.: Particle backscatter and relative humidity measured across cirrus clouds and comparison with microphysical cirrus modelling, Atmos. Chem. Phys., 12, 9135-9148, doi:10.5194/acp-12-9135-2012, 2012.

Carslaw, K. S., Wirth, M., Tsias, A., Luo, B. P., Dörnbrack, A., Leutbecher, M., Volkert, H., Renger, W., Bacmeister, J. T., Reimer, E., and Peter, T.: Increased stratospheric ozone depletion due to mountain-induced atmospheric waves, Nature, 391, 675-678, doi:10.1038/35589, 1998.

Chang, H.-Y. A., Koop, T., Molina, L. T., and Molina, M. J.: Phase Transitions in Emulsified $\mathrm{HNO}_{3} / \mathrm{H}_{2} \mathrm{O}$ and $\mathrm{HNO}_{3} / \mathrm{H}_{2} \mathrm{SO}_{4} / \mathrm{H}_{2} \mathrm{O}$ Solutions, J. Phys. Chem., 103, 2673-2679, doi:10.1021/jp9841034, 1999.

Curtius, J., Weigel, R., Vossing, H. J., Wernli, H., Werner, A., Volk, C. M., Konopka, P., Krebsbach, M., Schiller, C., Roiger, A., Schlager, H., Dreiling, V., and Borrmann, S.: Observations of meteoric material and implications for aerosol nucleation in the winter Arctic lower stratosphere derived from in situ particle measurements, Atmos. Chem. Phys., 5, 3053-3069, doi:10.5194/acp-5-3053-2005, 2005.

Cziczo, D. J., Thomson, D. S., and Murphy, D. M.: Ablation, flux, and atmospheric implications of meteors inferred from stratospheric aerosol, Science, 291, 1772-1775, doi:10.1126/science.1057737, 2001.

Cziczo, D. J., Froyd, K. D., Hoose, C., Jensen, E. J., Diao, M., Zondlo, M. A., Smith, J. B., Twohy, C. H., and Murphy, D. M.: Clarifying the Dominant Sources and Mechanisms of Cirrus Cloud Formation, Science, 340, 1320-1324, doi:10.1126/science.1234145, 2013.

Dee, D. P., Uppala, S. M., Simmons, A. J., Berrisford, P., Poli, P., Kobayashi, S., Andrae, U., Balmaseda, M. A., Balsamo, G., Bauer, P., Bechtold, P., Beljaars, A. C. M., van de Berg, L., Bidlot, J., Bormann, N., Delsol, C., Dragani, R., Fuentes, M., Geer, A. J., Haimberger, L., Healy, S. B., Hersbach, H., Hólm, E. V., Isaksen, L., Kållberg, P., Köhler, M., Matricardi, M., McNally, A. P., Monge-Sanz, B. M., Morcrette, J.-J., Park, B.-K., Peubey, C., de Rosnay, P., Tavolato, C., Thépaut, J.-N., and Vitart, F.: 
The ERA-Interim reanalysis: configuration and performance of the data assimilation system, Quart. J. Roy. Meteorol. Soc., 137, 553-597, doi:10.1002/qj.828, 2011.

DeMott, P. J., Cziczo, D. J., Prenni, A. J., Murphy, D. M., Kreidenweis, S. M., Thomson, D. S., Borys, R., and Rogers, D. C.: Measurements of the concentration and composition of nuclei for cirrus formation, Proc. Nat. Acad. Sci. USA, 100, 14655-14660, doi:10.1073/pnas.2532677100, 2003.

Dörnbrack, A., Leutbecher, M., Kivi, R., and Kyrö, E.: Mountain-wave-induced record low stratospheric temperatures above northern Scandinavia, Tellus A, 51, 951-963, doi:10.1034/j.1600-0870.1999.00028.x, 1999.

Dörnbrack, A., Pitts, M. C., Poole, L. R., Orsolini, Y. J., Nishii, K., and Nakamura, H.: The 2009-2010 arctic stratospheric winter general evolution, mountain waves and predictability of an operational weather forecast model, Atmos. Chem. Phys., 12, 36593675, doi:10.5194/acp-12-3659-2012, 2012.

Dye, J. E., Baumgardner, D., Gandrud, B. W., Kawa, S. R., Kelly, K. K., Loewenstein, M., Ferry, G. V., Chan, K. R., and Gary, B. L.: Particle Size Distributions in Arctic Polar Stratospheric Clouds, Growth and Freezing of Sulfuric Acid Droplets, and Implications for Cloud Formation, J. Geophys. Res., 97, 80158034, 1992.

Farman, J. C., Gardiner, B. G., and Shanklin, J. D.: Large losses of total ozone in Antarctica reveal seasonal $\mathrm{ClO} X / \mathrm{NO}_{X}$ interaction, Nature, 315, 207-210, doi:10.1038/315207a0, 1985.

Fritts, D. C. and Alexander, M. J.: Gravity wave dynamics and effects in the middle atmosphere, Rev. Geophys., 41, 1003, doi:10.1029/2001RG000106, 2003.

Fueglistaler, S., Buss, S., Luo, B. P., Wernli, H., Flentje, H., Hostetler, C. A., Poole, L. R., Carslaw, K. S., and Peter, T.: Detailed modeling of mountain wave PSCs, Atmos. Chem. Phys., 3, 697-712, doi:10.5194/acp-3-697-2003, 2003.

Gary, B. L.: Mesoscale temperature fluctuations in the stratosphere, Atmos. Chem. Phys., 6, 4577-4589, doi:10.5194/acp-6-45772006, 2006.

Grooß, J.-U., Engel, I., Borrmann, S., Frey, W., Günther, G., Hoyle, C. R., Kivi, R., Luo, B. P., Molleker, S., Peter, T., Pitts, M. C., Schlager, H., Stiller, G., Vömel, H., Walker, K. A., and Müller, R.: NAT nucleation and denitrification in the Arctic stratosphere, Atmos. Chem. Phys. Discuss., 13, 22107-22150, doi:10.5194/acpd-13-22107-2013, 2013.

Hoyle, C. R., Engel, I., Luo, B. P., Pitts, M. C., Poole, L. R., Grooß, J.-U., and Peter, T.: Heterogeneous formation of polar stratospheric clouds - Part 1: Nucleation of nitric acid trihydrate (NAT), Atmos. Chem. Phys., 13, 9577-9595, doi:10.5194/acp13-9577-2013, 2013.

Hoyle, C. R., Luo, B. P., and Peter, T.: The origin of high ice crystal number densities in cirrus clouds, J. Atmos. Sci., 62, 2568-2579, doi:10.1175/JAS3487.1, 2005.

Hunt, W. H., Winker, D. M., Vaughan, M. A., Powell, K. A., Lucker, P. L., and Weimer, C.: CALIPSO Lidar Description and Performance Assessment, J. Atmos. Ocean. Technol., 26, 1214-1228, doi:10.1175/2009JTECHA1223.1, 2009.

Hunten, D. M., Turco, R. P., and Toon, O. B.: Smoke and Dust Particles of Meteoric Origin in the Mesosphere and Stratosphere, J. Atmos. Sci., 37, 1342-1357, doi:10.1175/15200469(1980)037<1342:SADPOM>2.0.CO;2, 1980.
Kärcher, B. and Lohmann, U.: A parameterization of cirrus cloud formation: Heterogeneous freezing, J. Geophys. Res., 108, 4402, doi:10.1029/2002JD003220, 2003.

Knopf, D. A., Koop, T., Luo, B. P., Weers, U. G., and Peter, T.: Homogeneous nucleation of NAD and NAT in liquid stratospheric aerosols: insufficient to explain denitrification, Atmos. Chem. Phys., 2, 207-214, doi:10.5194/acp-2-207-2002, 2002.

Koop, T., Ng, H. P., Molina, L. T., and Molina, M. J.: A New Optical Technique to Study Aerosol Phase Transitions: The Nucleation of Ice from $\mathrm{H}_{2} \mathrm{SO}_{4}$ Aerosols, J. Phys. Chem., 102, 8924-8931, doi:10.1021/jp9828078, 1998.

Koop, T., Biermann, U. M., Raber, W., Luo, B. P., Crutzen, P. J., and Peter, T.: Do stratospheric aerosol droplets freeze above the ice frost point?, Geophys. Res. Lett., 22, 917-920, doi:10.1029/95GL00814, 1995.

Koop, T., Luo, B. P., Tsias, A., and Peter, T.: Water activity as the determinant for homogeneous ice nucleation in aqueous solutions, Nature, 406, 611-614, doi:10.1038/35020537, 2000.

Lambert, A., Read, W. G., Livesey, N. J., Santee, M. L., Manney, G. L., Froidevaux, L., Wu, D. L., Schwartz, M. J., Pumphrey, H. C., Jimenez, C., Nedoluha, G. E., Cofield, R. E., Cuddy, D. T., Daffer, W. H., Drouin, B. J., Fuller, R. A., Jarnot, R. F., Knosp, B. W., Pickett, H. M., Perun, V. S., Snyder, W. V., Stek, P. C., Thurstans, R. P., Wagner, P. A., Waters, J. W., Jucks, K. W., Toon, G. C., Stachnik, R. A., Bernath, P. F., Boone, C. D., Walker, K. A., Urban, J., Murtagh, D., Elkins, J. W., and Atlas, E.: Validation of the Aura Microwave Limb Sounder middle atmosphere water vapor and nitrous oxide measurements, J. Geophys. Res., 112, 4402, doi:10.1029/2007JD008724, 2007.

Lambert, A., Santee, M. L., Wu, D. L., and Chae, J. H.: A-train CALIOP and MLS observations of early winter Antarctic polar stratospheric clouds and nitric acid in 2008, Atmos. Chem. Phys., 12, 2899-2931, doi:10.5194/acp-12-2899-2012, 2012.

Liu, L. and Mishchenko, M. I.: Constraints on PSC particle microphysics derived from lidar observations, J. Quant. Spectrosc. Radiat. Transf., 70, 817-831, doi:10.1016/S0022-4073(01)000486, 2001.

Lowe, D. and MacKenzie, A. R.: Polar stratospheric cloud microphysics and chemistry, J. Atmos. Solar-Terr. Phys., 70, 13-40, doi:10.1016/j.jastp.2007.09.011, 2008.

Luo, B. P., Carslaw, K. S., Peter, T., and Clegg, S. L.: Vapour pressures of $\mathrm{H}_{2} \mathrm{SO}_{4} / \mathrm{HNO}_{3} / \mathrm{HCl} / \mathrm{HBr} / \mathrm{H}_{2} \mathrm{O}$ solutions to low stratospheric temperatures, Geophys. Res. Lett., 22, 247-250, doi:10.1029/94GL02988, 1995.

Luo, B. P., Voigt, C., Fueglistaler, S., and Peter, T.: Extreme NAT supersaturations in mountain wave ice PSCs: A clue to NAT formation, J. Geophys. Res., 108, D24S36, doi:10.1029/2002JD003104, 2003.

Manney, G. L., Sabutis, J. L., Pawson, S., Santee, M. L., Naujokat, B., Swinbank, R., Gelman, M. E., and Ebisuzaki, W.: Lower stratospheric temperature differences between meteorological analyses in two cold Arctic winters and their impact on polar processing studies, J. Geophys. Res., 108, 4441, doi:10.1029/2001JD001149, 2003.

Marcolli, C., Gedamke, S., Peter, T., and Zobrist, B.: Efficiency of immersion mode ice nucleation on surrogates of mineral dust, Atmos. Chem. Phys., 7, 5081-5091, 2007.

McKenna, D. S., Konopka, P., Grooß, J.-U., Günther, G., Müller, R., Spang, R., Offermann, D., and Orsolini, Y.: A new Chem- 
ical Lagrangian Model of the Stratosphere (CLaMS) - 1. Formulation of advection and mixing, J. Geophys. Res., 107, 8328, doi:10.1029/2000JD000114, 2002.

Meilinger, S. K., Koop, T., Luo, B. P., Huthwelker, T., Carslaw, K. S., Krieger, U., Crutzen, P. J., and Peter, T.: Size-dependent stratospheric droplet composition in lee wave temperature fluctuations and their potential role in PSC freezing, Geophys. Res. Lett., 22, 3031-3034, doi:10.1029/95GL03056, 1995.

Mewaldt, R. A., Cohen, C. M. S., Mason, G. M., von Rosenvinge, T. T., Leske, R. A., Luhmann, J. G., Odstrcil, D., and Vourlidas, A.: Solar energetic particles and their variability from the sun and beyond, AIP Conf. Proc., 1539, 116-121, doi:10.1063/1.4811002, 2013.

Middlebrook, A. M., Iraci, L. T., McNeill, L. S., Koehler, B. G., Wilson, M. A., Saastad, O. W., Tolbert, M. A., and Hanson, D. R.: Fourier transform-infrared studies of thin $\mathrm{H}_{2} \mathrm{SO}_{4} / \mathrm{H}_{2} \mathrm{O}$ films: Formation, water uptake, and solid-liquid phase changes, J. Geophys. Res., 98, 20473-20481, doi:10.1029/93JD02454, 1993.

Mishchenko, M. I., Travis, L. D., and Mackowski, D. W.: T-Matrix Computations of Light Scattering by Nonspherical Particles: A Review (Reprinted from vol 55, pg 535-575, 1996), J. Quant. Spectrosc. Radiat. Transf., 111, 1704-1744, doi:10.1016/00224073(96)00002-7, 2010.

Murphy, D. M. and Gary, B. L.: Mesosclae Temperature Fluctuations and Polar Stratospheric Clouds, J. Atmos. Sci., 52, 1753-1760, doi:10.1175/15200469(1995)052<1753:MTFAPS>2.0.CO;2, 1995.

Murphy, D. M. and Koop, T.: Review of the vapour pressures of ice and supercooled water for atmospheric applications, Q. J. Roy. Meteorol. Soc., 131, 1539-1565, doi:10.1256/qj.04.94, 2005.

Peter, T.: Microphysics and Heterogeneous Chemistry of Polar Stratospheric Clouds, Annu. Rev. Phys. Chem., 48, 785-822, doi:10.1146/annurev.physchem.48.1.785, 1997.

Peter, T. and Grooß, J.-U.: Chapter 4: Polar Stratospheric Clouds and Sulfate Aerosol Particles: Microphysics, Denitrification and Heterogeneous Chemistry, in: Stratospheric Ozone Depletion and Climate Change, Roy. Soc. Chem., 108-144, doi:10.1039/9781849733182-00108, 2012.

Pitts, M. C., Poole, L. R., and Thomason, L. W.: CALIPSO polar stratospheric cloud observations: second-generation detection algorithm and composition discrimination, Atmos. Chem. Phys., 9, 7577-7589, doi:10.5194/acp-9-7577-2009, 2009.

Pitts, M. C., Poole, L. R., Dörnbrack, A., and Thomason, L. W.: The 2009-2010 Arctic polar stratospheric cloud season: a CALIPSO perspective, Atmos. Chem. Phys., 11, 2161-2177, doi:10.5194/acp-11-2161-2011, 2011.

Pitzer, K.: Activity coefficients in electrolyte solutions, CRC Press, 1991.

Plane, J. M. C.: Cosmic dust in the earth's atmosphere, Chem. Soc. Rev., 41, 6507-6518, doi:10.1039/C2CS35132C, 2012.

Pruppacher, H. R. and Klett, J. D.: Microphysics of clouds and precipitation, Atmospheric and oceanographic sciences library, Kluwer Academic Publishers, Chapter 9, 1996.

Read, W. G., Lambert, A., Bacmeister, J., Cofield, R. E., Christensen, L. E., Cuddy, D. T., Daffer, W. H., Drouin, B. J., Fetzer, E., Froidevaux, L., Fuller, R., Herman, R., Jarnot, R. F., Jiang, J. H., Jiang, Y. B., Kelly, K., Knosp, B. W., Kovalenko, L. J., Livesey, N. J., Liu, H.-C., Manney, G. L., Pickett, H. M., Pumphrey, H. C., Rosenlof, K. H., Sabounchi, X., Santee, M. L.,
Schwartz, M. J., Snyder, W. V., Stek, P. C., Su, H., Takacs, L. L., Thurstans, R. P., Vömel, H., Wagner, P. A., Waters, J. W., Webster, C. R., Weinstock, E. M., and Wu, D. L.: Aura Microwave Limb Sounder upper tropospheric and lower stratospheric $\mathrm{H}_{2} \mathrm{O}$ and relative humidity with respect to ice validation, J. Geophys. Res., 112, D24S35, doi:10.1029/2007JD008752, 2007.

Santee, M. L., Lambert, A., Read, W. G., Livesey, N. J., Cofield, R. E., Cuddy, D. T., Daffer, W. H., Drouin, B. J., Froidevaux, L., Fuller, R. A., Jarnot, R. F., Knosp, B. W., Manney, G. L., Perun, V. S., Snyder, W. V., Stek, P. C., Thurstans, R. P., Wagner, P. A., Waters, J. W., Muscari, G., de Zafra, R. L., Dibb, J. E., Fahey, D. W., Popp, P. J., Marcy, T. P., Jucks, K. W., Toon, G. C., Stachnik, R. A., Bernath, P. F., Boone, C. D., Walker, K. A., Urban, J., and Murtagh, D.: Validation of the Aura Microwave Limb Sounder $\mathrm{HNO}_{3}$ measurements, J. Geophys. Res., 112, D24S40, doi:10.1029/2007JD008721, 2007.

Seinfeld, J. H. and Pandis, S. N.: Atmospheric chemistry and physics: from air pollution to climate change, A WileyIntersciencie publications, Wiley, 524-526, 2006.

Solomon, S.: The hole truth - What's news (and what's not) about the ozone hole., Nature, 427, 289-291, doi:10.1038/427289a, 2004.

Solomon, S., Garcia, R. R., Rowland, F. S., and Wuebbles, D. J.: On the depletion of Antarctic ozone, Nature, 321, 755-758, doi:10.1038/321755a0, 1986.

SPARC (Stratospheric Processes And their Role in Climate): SPARC Assessment of Stratospheric Aerosol Properties, edited by L. W. Thomason and T. Peter, WCRP-124, SPARC Report 4, WMO/TD-No.1295, 346 pp., 2006.

Stanford, J. L. and Davis, J. S.: A century of stratospheric cloud reorts: 1870-1972, B. Am. Meteorol. Soc., 55, 213-219, 1974.

Tabazadeh, A., Djikaev, Y. S., and Reiss, H.: Surface crystallization of supercooled water in clouds, PNAS, 99, 15873-15878, doi:10.1073/pnas.252640699, 2002.

von Hobe, M., Bekki, S., Borrmann, S., Cairo, F., D’Amato, F., Di Donfrancesco, G., Dörnbrack, A., Ebersoldt, A., Ebert, M., Emde, C., Engel, I., Ern, M., Frey, W., Genco, S., Griessbach, S., Grooß, J.-U., Gulde, T., Günther, G., Hösen, E., Hoffmann, L., Homonnai, V., Hoyle, C. R., Isaksen, I. S. A., Jackson, D. R., Jánosi, I. M., Jones, R. L., Kandler, K., Kalicinsky, C., Keil, A., Khaykin, S. M., Khosrawi, F., Kivi, R., Kuttippurath, J., Laube, J. C., Lefèvre, F., Lehmann, R., Ludmann, S., Luo, B. P., Marchand, M., Meyer, J., Mitev, V., Molleker, S., Müller, R., Oelhaf, H., Olschewski, F., Orsolini, Y., Peter, T., Pfeilsticker, K., Piesch, C., Pitts, M. C., Poole, L. R., Pope, F. D., Ravegnani, F., Rex, M., Riese, M., Röckmann, T., Rognerud, B., Roiger, A., Rolf, C., Santee, M. L., Scheibe, M., Schiller, C., Schlager, H., Siciliani de Cumis, M., Sitnikov, N., Søvde, O. A., Spang, R., Spelten, N., Stordal, F., Suminska-Ebersoldt, O., Ulanovski, A., Ungermann, J., Viciani, S., Volk, C. M., vom Scheidt, M., von der Gathen, P., Walker, K., Wegner, T., Weigel, R., Weinbruch, S., Wetzel, G., Wienhold, F. G., Wohltmann, I., Woiwode, W., Young, I. A. K., Yushkov, V., Zobrist, B., and Stroh, F.: Reconciliation of essential process parameters for an enhanced predictability of Arctic stratospheric ozone loss and its climate interactions (RECONCILE): activities and results, Atmos. Chem. Phys., 13, 9233 9268, doi:10.5194/acp-13-9233-2013, 2013.

Waters, J. W., Froidevaux, L., Harwood, R. S., Jarnot, R. F., Pickett, H. M., Read, W. G., Siegel, P. H., Cofield, R. E., Filipiak, M. J., 
Flower, D. A., Holden, J. R., Lau, G. K. K., Livesey, N. J., Manney, G. L., Pumphrey, H. C., Santee, M. L., Wu, D. L., Cuddy, D. T., Lay, R. R., Loo, M. S., Perun, V. S., Schwartz, M. J., Stek, P. C., Thurstans, R. P., Boyles, M. A., Chandra, K. M., Chavez, M. C., Chen, G. S., Chudasama, B. V., Dodge, R., Fuller, R. A., Girard, M. A., Jiang, J. H., Jiang, Y. B., Knosp, B. W., LaBelle, R. C., Lam, J. C., Lee, K. A., Miller, D., Oswald, J. E., Patel, N. C., Pukala, D. M., Quintero, O., Scaff, D. M., Van Snyder, W., Tope, M. C., Wagner, P. A., and Walch, M. J.: The Earth Observing System Microwave Limb Sounder (EOS MLS) on the Aura satellite, IEEE Trans. Geosci. Remote Sens., 44, 10751092, doi:10.1109/TGRS.2006.873771, 2006.

Winker, D. M., Vaughan, M. A., Omar, A., Hu, Y., Powell, K. A., Liu, Z., Hunt, W. H., and Young, S. A.: Overview of the CALIPSO Mission and CALIOP Data Processing Algorithms, J. Atmos. Ocean. Technol., 26, 2310-2323, doi:10.1175/2009JTECHA1281.1, 2009.

Winker, D. M., Hunt, W. H., and McGill, M. J.: Initial performance assessment of CALIOP, Geophys. Res. Lett., 34, L19803, doi:10.1029/2007GL030135, 2007.
World Meteorological Organization (WMO): Scientific Assessment of Ozone Depletion, WMO Global Ozone Research and Monitoring Project - Report No. 44, Geneva, 1998.

Yu, F.: Formation of large NAT particles and denitrification in polar stratosphere: possible role of cosmic rays and effect of solar activity, Atmos. Chem. Phys., 4, 2273-2283, doi:10.5194/acp-42273-2004, 2004.

Zobrist, B., Koop, T., Luo, B. P., Marcolli, C., and Peter, T.: Heterogeneous ice nucleation rate coefficient of water droplets coated by a nonadecanol monolayer, J. Phys. Chem., 111, 2149-2155, doi:10.1021/jp066080w, 2007.

Zuberi, B., Bertram, A. K., Cassa, C. A., Molina, L. T., and Molina, M. J.: Heterogeneous nucleation of ice in $\left(\mathrm{NH}_{4}\right)_{2} \mathrm{SO}_{4}-\mathrm{H}_{2} \mathrm{O}$ particles with mineral dust immersions, Geophys. Res. Lett., 29, 1504, doi:10.1029/2001GL014289, 2002. 